\title{
THE SURPRISING INSTABILITY OF EXPORT SPECIALIZATIONS
}

\author{
Diego Daruich \\ William Easterly \\ Ariell Reshef \\ Working Paper 22869 \\ http://www.nber.org/papers/w22869 \\ NATIONAL BUREAU OF ECONOMIC RESEARCH \\ 1050 Massachusetts Avenue \\ Cambridge, MA 02138 \\ November 2016
}

We are grateful for comments from participants in the NYU Development Research Institute Conference "Beyond the Nation State,"and for comments from Xavier Gabaix, Ricardo Hausmann, and Dani Rodrik. We are also grateful for funding from the Templeton Foundation. The views expressed here are not necessarily those of the Templeton Foundation or the National Bureau of Economic Research.

NBER working papers are circulated for discussion and comment purposes. They have not been peer-reviewed or been subject to the review by the NBER Board of Directors that accompanies official NBER publications.

(C) 2016 by Diego Daruich, William Easterly, and Ariell Reshef. All rights reserved. Short sections of text, not to exceed two paragraphs, may be quoted without explicit permission provided that full credit, including ( $)$ notice, is given to the source. 
The Surprising Instability of Export Specializations

Diego Daruich, William Easterly, and Ariell Reshef

NBER Working Paper No. 22869

November 2016

JEL No. F1,F14,F63,O1,O24

\section{ABSTRACT}

We study the instability of hyper-specialization of exports. We have two main findings. (1) Specializations are surprisingly unstable: Export ranks are not persistent, and new top products and destinations replace old ones. Measurement error is unlikely to be the main or only determinant of this pattern. (2) Source-country factors are not the main explanation of this instability: Only $20 \%$ of the variation in export growth can be explained by variation in comparative advantage (source-by-product factors), while another $20 \%$ of the variation in export growth can be explained by variation in bilateral (source-by-destination) factors. The high share of product, destination, and product-by-destination factors, diminishes the emphasis on the nations where the exports originate. The high share of idiosyncratic variance (residual at the source-product-destination level of variation) of about $30 \%$, also indicates the difficulty to predict export success using source country characteristics. These findings suggest that export performance depends, to a greater extent than previously appreciated, on forces that are outside the realm of national export promotion and industrial policies.

Diego Daruich

NYU Department of Economics

19 West 4th Street, 6th floor

New York NY 10012

ddaruich@nyu.edu

William Easterly

New York University

Department of Economics

19 W. 4th Street, 6th floor

New York NY 10012

and NBER

william.easterly@nyu.edu
Ariell Reshef

Université Paris 1 - Panthéon Sorbonne

Maison des Sciences Economiques

Bureau 310

106-112 Boulevard de l'Hopital

75647 Paris Cedex 13

France

and CNRS, Paris School of Economics, and CEPII ariell.reshef@psemail.eu 


\section{Introduction}

What are the roads to economic development? Part of the answer lies in success in international trade (Frankel and Romer 1999). ${ }^{1}$ Informed observation of the Asian Tigers and China's recent experience demonstrates this effect. Whatever the sources of comparative advantage may be - technology (Ricardo), endowments (Heckscher and Ohlin), geography (Frankel and Romer 1999, structural gravity equations), the interaction between geography and technology (Eaton and Kortum 2002) or institutions (Nunn 2007, Levchenko 2007) - high income is tightly correlated with success in exporting and reaping the gains from trade. ${ }^{2}$ Figure 1 is suggestive of this for a cross section of 96 countries: The correlation between success in exporting and success measured by income per capita is 0.92 .

In this paper we study the instability of export flows over time, and we pay special attention to top export flows. Hyper-specialization in exports has been previously documented, as we discuss below. Our main contribution, however, is to document the instability of top exports. This is important because top exports account for most of the value of exports and, as we demonstrate below, it is the top exports that are correlated with development. Yet it is surprising how unpredictable which good and which destination make up the top exports.

We analyze instability in a number of non-parametric ways. First, graphically, we illustrate how the ranking of export goods changes over time, from 1998 to 2010, for a set of countries of different levels of development. These detailed charts make clear what kind of products are involved in both hyper-specialization and just how unstable these

\footnotetext{
${ }^{1}$ Siscart and Noguer (2005) corroborate the findings of Frankel and Romer (1999) with improved methodology and data.

2 Easterly and Reshef (2016) document other sources of export success in Africa, such as moving up the quality ladder, trade liberalization, foreign ownership, ethnic networks, and personal foreign experience of the exporting entrepreneur, as well as idiosyncratic factors like entrepreneurial persistence, luck, and cost shocks. Some of the successes occur in areas that usually fail. See also Artopolus, Friel and Hallak (2010) for examples from Argentina.
} 
hyper-specializations are. Our analysis uses 4-digit HS codes to identify products (there are 1225 such codes). This level of aggregation is enough to eliminate much of the idiosyncratic variation (such as measurement error due to misclassification) without sacrificing a clear notion of differentiation in the product space.

More systematically, we show that correlations between export ranks in 1998 and 2010 are surprisingly low, on the order of only 0.3 . We analyze the probability of remaining a top export in 2010 conditional on being a top export in 1998, and find that this increases with the level of development, which implies that exports from developing countries tend to be more unstable. This is true whether we study trade flows at the product or at the product-by-destination level (which we will call export "flows"). We illustrate that export instability is not driven primarily by measurement error.

Finally, we analyze the sources of export instability. We develop a methodology to decompose the sources of variation in export growth along several dimensions, as well as their interactions (e.g., the source-by-product interaction, which captures variation in comparative advantage). While analysis and public policy discussion often attribute changes in export performance to the source country, we consider the role of other factors beyond the source country - trends in global demand, global trade trends by product, effects of demand in the destination country (both in general and for specific products in that destination), and effects specific to the source-destination combination (such as the changing importance of distance, the bilateral manifestation of trade agreements, and other bilateral "gravity" forces).

Our results indicate that changes in comparative advantage alone (source-by-product) account for only $20 \%$ of the variation in export growth. Another $20 \%$ of the variation is accounted for by bilateral factors. This suggests that explanations for export success that focus only on comparative advantage in the source country (and the policies that affect gains from comparative advantage) may be missing much of the origins of success. 
It is also notable that the sum of product and destination effects on variation in export growth are slightly larger than the sum of effects involving the source country (sourceby-product effects plus source-by-destination effects, even with the latter not being completely driven by the source country). Overall, the results suggest that most of the variability in export growth is not driven by source country factors. This suggests that too much export success or failure may be attributed to the source countries, as opposed to external and global factors. While local entrepreneurs and firms may be active in locating and reaping these external opportunities, our analysis indicates that these opportunities are not driven by source-country forces per se. In line with this, about one-third of export growth of top products and half of export growth for all products can only be attributed to completely idiosyncratic shocks. ${ }^{3}$

The rest of the paper is organized as follows. Section II presents some facts about the relationship between exports and income, and discusses our contribution to the existing literature. Section III describes our data. Section IV presents our results about export concentration and instability. Section V analyzes the sources of instability. Section VI concludes.

\section{Stylized Facts and Previous Literature}

Figure 1 showed the high correlation between success in exporting and income. ${ }^{4}$ Figure 2 shows that this relationship can be summarized by observing only the top 20 (4-digit HS codes) exported products, with a correlation that is almost as high, at 0.90 . This motivates a more forensic examination of the most important part of export flows, at the upper tail

\footnotetext{
3 We also find that variation in export growth in richer economies and in countries that have more diversified exports across destinations is driven even less by variation in comparative advantage and bilateral ties.

4 In an Eaton and Kortum (2002) model, both export success and income are driven by the level of technology. A country with better technology, i.e. absolute advantage, will have higher income, partially because it can supply its goods more cheaply to other destinations. This model is static and says nothing about instability.
} 
of the export size distribution. Figure 3 shows that this relationship holds with a very high correlation of 0.85 , even when we consider the top 20 exports flows, where a flow is defined as a particular 4-digit product shipped to a particular destination country. The signature feature of figures 1-3 is how similar they are. This resemblance demonstrates an under-appreciated dimension of hyper-specialization: most products are shipped to very few destinations, and the modal number of destinations per good exported is $1 .^{5}$

Export success is concentrated on relatively few goods and, consequently, success in exporting is driven by a few big hits. Table 1 demonstrates that the top 20 goods that a country exports (out of a maximum of 1225 4-digit HS codes) account for almost $70 \%$ of total exports. This pattern is not just driven by commodities and extractables exports that are more prevalent in low income countries such as African ones. African and other nonOECD countries are of particular interest because in our sample they see faster export growth, as demonstrated in Figure 4.

\footnotetext{
5 The correlation between $\log$ total exports and the exports of top 20 goods is 0.99 , and between log total exports and the exports of top 20 flows (good by destination) is 0.85 .
} 


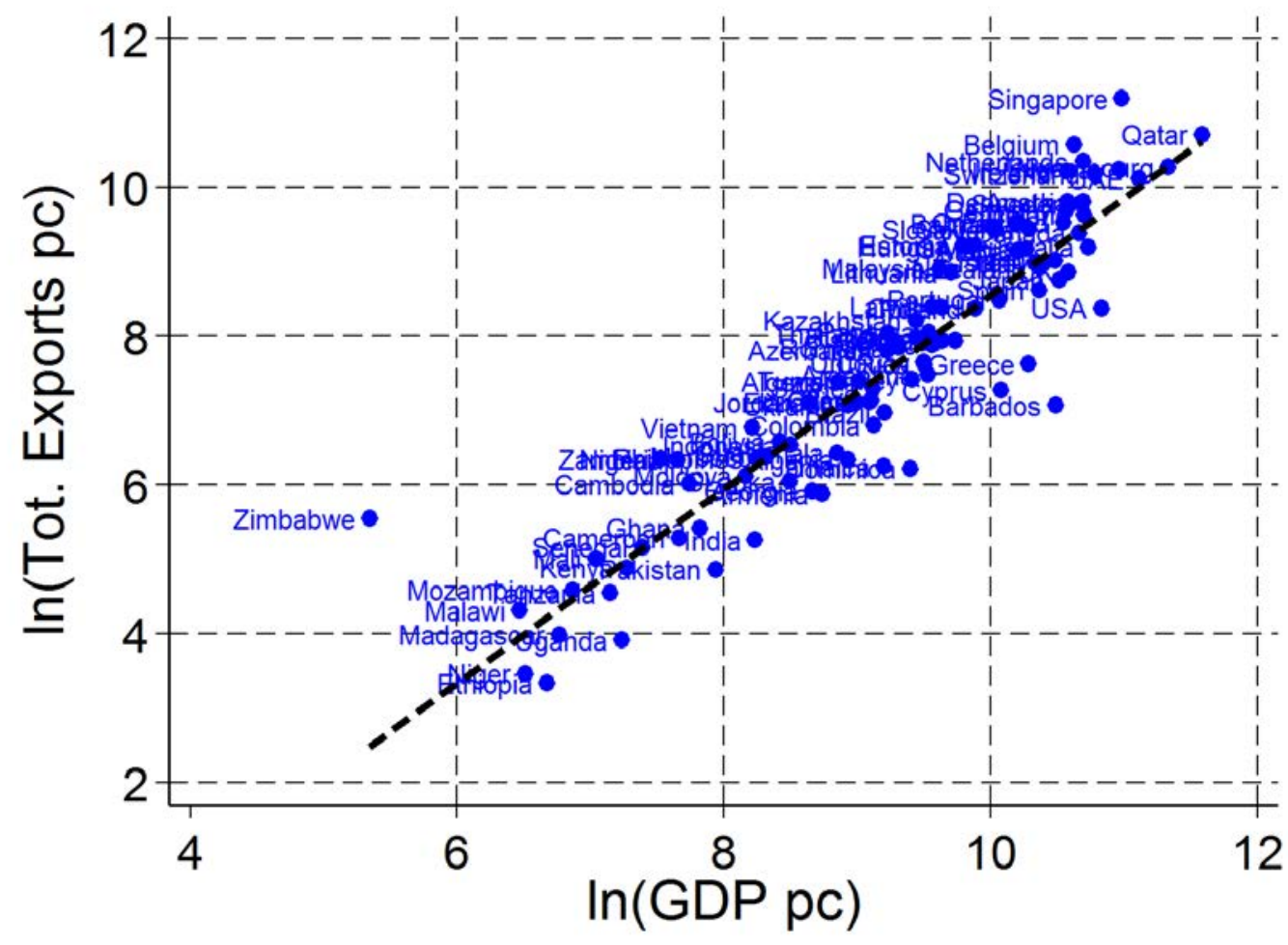

Figure 1: Total Exports per capita and development (GDP in PPP per capita) are highly correlated, with correlation coefficient equal to 0.92. Source: COMTRADE and Total Economy Database. Data in 2010. Number of countries: 112. 


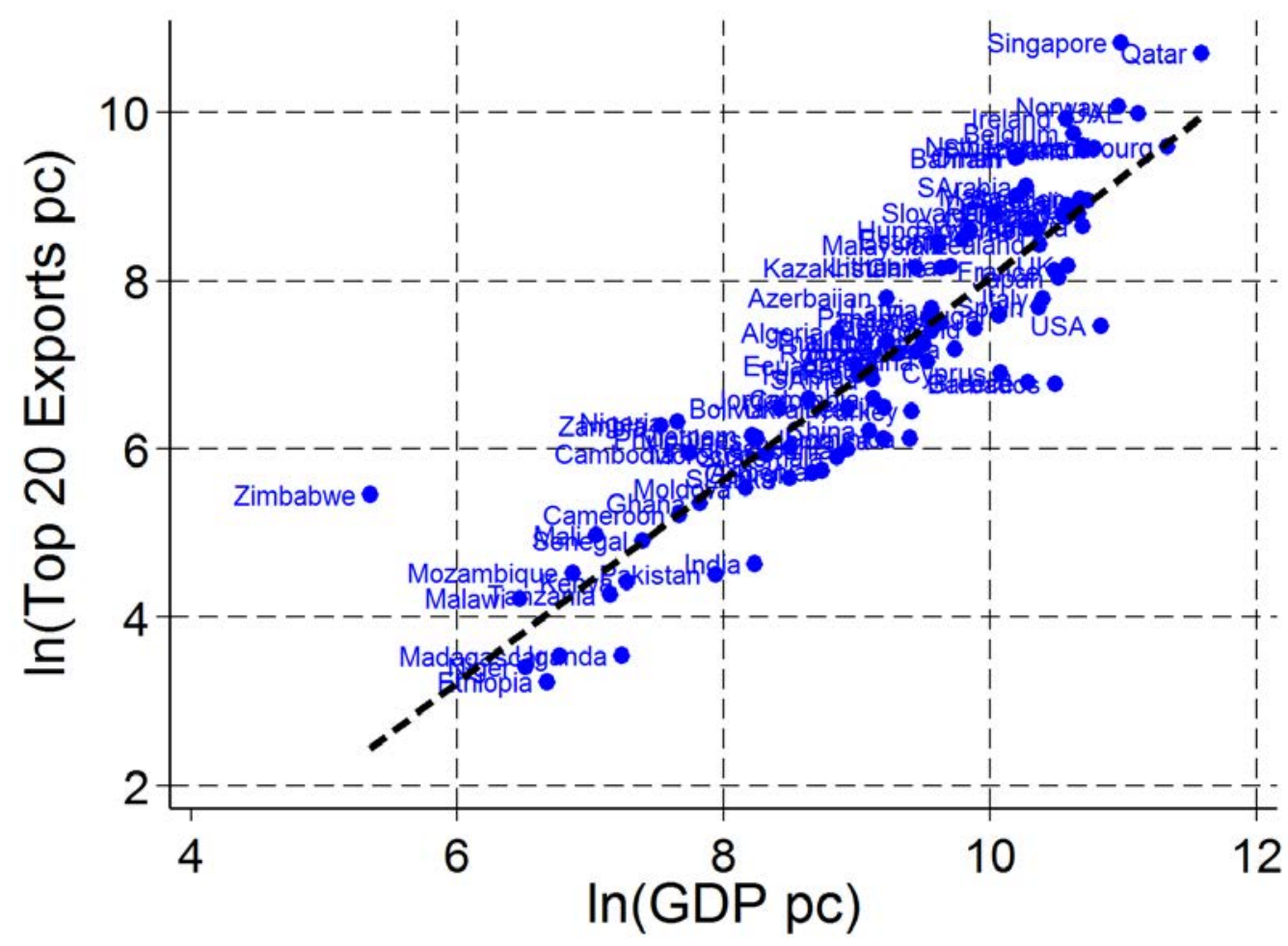

Figure 2: Top 20 exported goods (4-digit HS codes) per capita and development (GDP in PPP per capita) are highly correlated, with correlation coefficient equal to 0.90. Source: COMTRADE and Total Economy Database. Data in 2010. Number of countries: 112. 


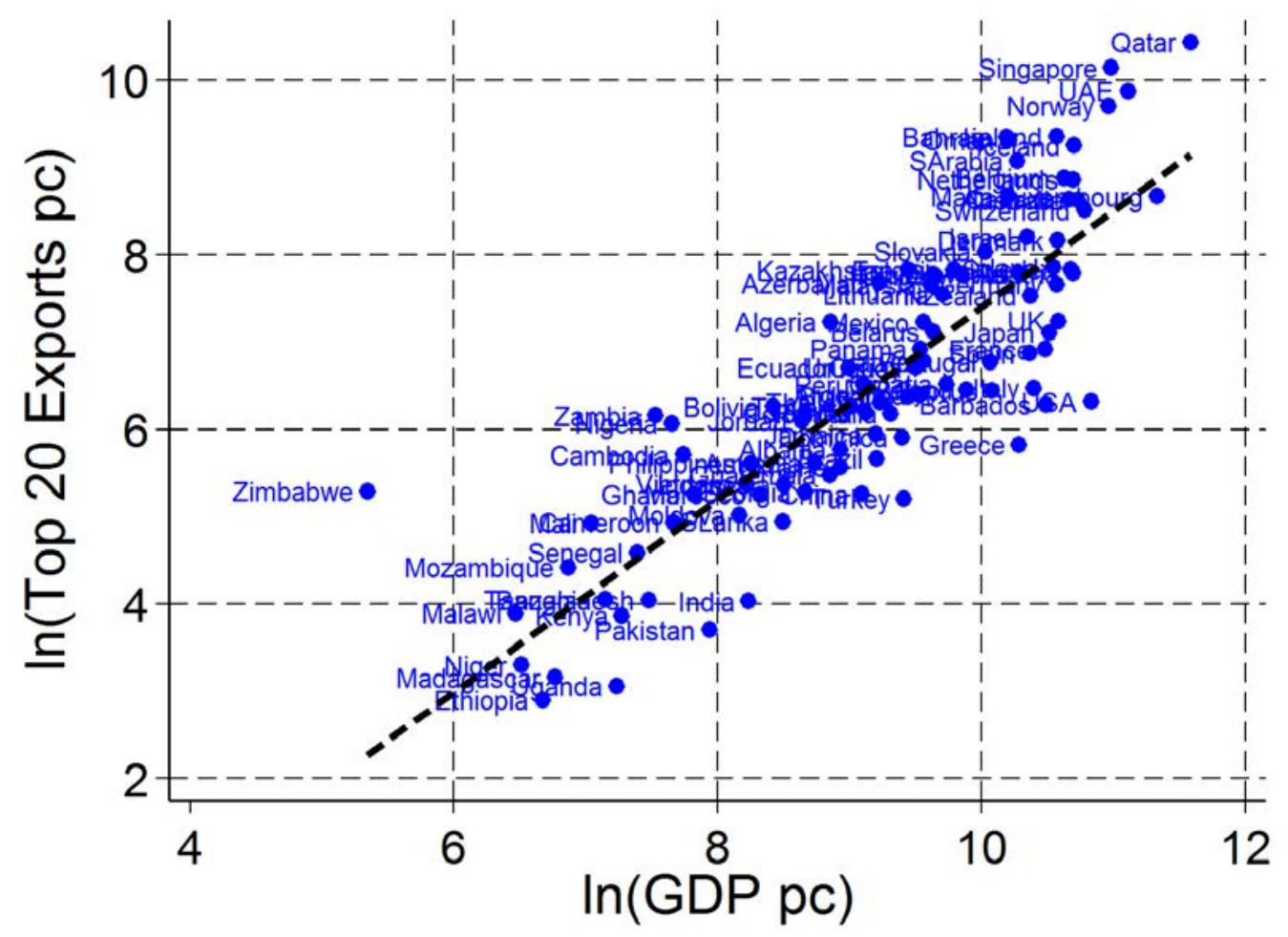

Figure 3: Top 20 export flows (4-digit HS codes by destination) per capita and development (GDP in PPP per capita) are highly correlated, with correlation coefficient equal to 0.85. Source: COMTRADE and Total Economy Database. Data in 2010. Number of countries: 112.

Our novel results on the instability of top export products have important implications for industrial policy and trade protection. The erratic evolution of exports over time questions the efficacy of protection policies that aim to promote exports by protecting or subsidizing the industrial base. For example, Hausmann and Rodrik (2006) argue that development occurs through a process of discovery of what a country is good at producing. Since this process involves positive information externalities that are not internalized by private actors, Hausmann and Rodrik (2006) advocate a subsidy for discovery. This is in line with how Cadot, Disdier, Jaud and Suwa-Eisenmann (2014) interpret their findings on export big hits, where they find little "crowding out" of firms that follow a pioneer exporting firm. However, if external demand (not technology) 
shocks are an important source of volatility of exports, then maybe it is less important or even impossible - to target specific industries. Hausmann, Hwang and Rodrik (2007) argue that a country's development converges to the level of countries that export similar goods. This is capturing a long-standing concern in development that some countries are trapped by their own characteristics into export patterns harmful to development, such as the 1949 Prebisch-Singer hypothesis that poor countries are stuck with producing and exporting commodities that are subject to declining terms of trade. ${ }^{6}$ However, if specialization across both destinations and products is so unstable, then perhaps what a country exports the most is not entirely an exporter-specific factor that dooms the country to a sub-optimal outcome, nor does it seem that countries are trapped in any one suboptimal specialization.

\footnotetext{
${ }^{6}$ See Harvey et al. (2010) and Arezki et al. (2013), who find mixed historical evidence on the validity of the PrebischSinger Hypothesis.
} 


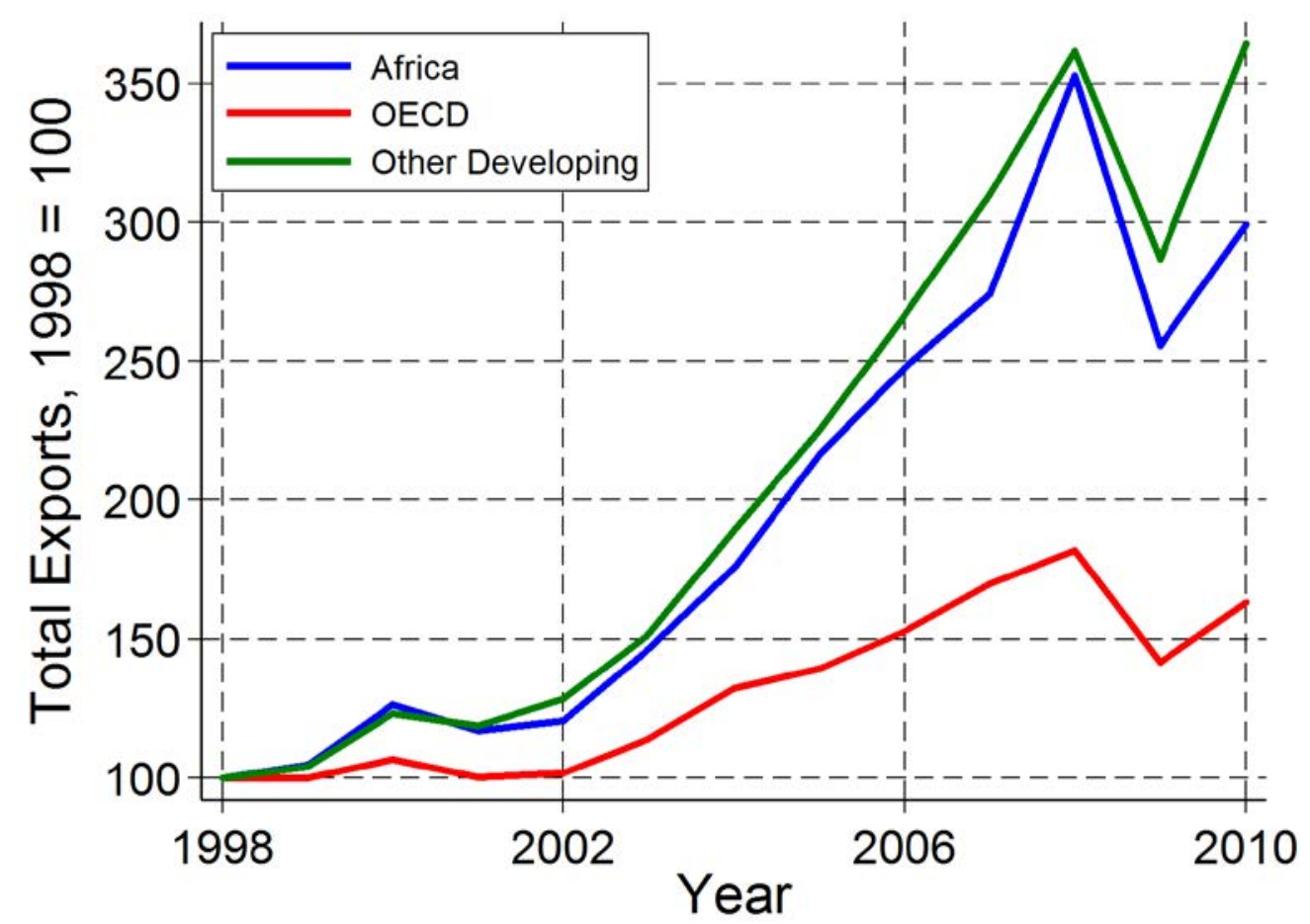

Figure 4: Export growth has been stronger in Africa and other developing countries, relative to OECD member countries. Each line depicts the average index of total exports for a subgroup of countries. Source: COMTRADE.

The concentration of exports has been noticed by other scholars. Eaton, Eslava, Kugler, and Tybout (2007) find that Colombian exports are driven by a small number of very large (and stable) exporting firms. Bernard, Jensen, Redding, and Schott (2007) document high concentration across U.S. exporting firms. Freund and Pierola (2015) show that this phenomenon is general, and can be found among 32 countries of varying levels of development. Panagariya and Bagaria (2013) show that concentration of exports and imports across products is strikingly similar, which is surprising because we expect comparative advantage to lead to much less concentration on the import side. Relative to these papers, we add the destination dimension of concentration, we study how concentration varies with income and overall export performance, and then we arrive at our main finding of the instability of the specializations. 
Cadot, Carrere and Strauss-Kahn (2011) estimate that concentration evolves as a UShape with economic development, being high at initial stages of development, low in the interim, and high concentration again for rich countries. ${ }^{7}$ Cadot et al. measure concentration using a Theil index, which is strongly influenced by differences between the largest values versus smaller values. ${ }^{8}$ In contrast, we examine export shares, which is arguably a more transparent and natural measure of concentration. We focus on the export shares of top exported goods or flows, which is the most important part of the distribution. In line with Cadot et al., we find that concentration is highest in the least developed countries, but we do not find strong evidence in favor of a reversal in the reduction in concentration after some level of development.

The novel part of our work is documenting and then analyzing the instability of exports. One source of exports volatility are demand shocks. Indeed, Eaton, Kortum and Kramarz (2011) estimate that demand is important for understanding the distribution of exports across firms in France, but they do not address volatility of demand (their model is designed for a cross section of export flows, and their estimation reflects this). Another potential source of volatility is technology. Trade models typically capture technological dispersion either as a power law (e.g., Baldwin, 2005, Helpman, Melitz and Rubinstein, 2008) or a Frechet distribution (Eaton and Kortum, 2002). Both of these distributions feature so-called "fat" tails. For theoretical tractability, in this class of models the distribution of exports (and of production) is allowed to vary only by location in the Frechet case, or is invariant in the power law case. ${ }^{9}$ Both shape and concentration of the distribution of exports seem to matter theoretically for aggregate fluctuations in "granular" economies with fat tails (e.g. Gabaix, 2011, di Giovanni and Levchenko,

\footnotetext{
7 This result is reminiscent of Imbs and Wacziarg (2003), who document a similar pattern for industrial production, not just exporting.

${ }^{8}$ Depending on the same underlying distribution, Theil and mean log difference can show different trends over time.

9 Helpman, Melitz and Yeaple (2004) model different variances of economic activity through differences in the Pareto slope coefficient. This helps them explain the tradeoff between serving foreign markets via exporting versus foreign direct investment. We also exploit the relationship between the size of the Pareto slope coefficient and variance below.
} 
2012, and di Giovanni, Levchenko and Mejan, 2014). We take an unrestricted, nonparametric approach to describing concentration and volatility of exports.

In another strand of related work, Besedes and Prusa (2006a) find that most trade relationships where the U.S. is an importer are short lived: Once started, they exhibit "negative duration", and African trade relationships with the U.S. are even shorter lived. This could give rise to volatility, due to entry and then exit. Besedes and Prusa (2006b) find that homogenous goods have much higher hazard rates, which can help explain the difference in relationship duration for Africa. Cadot, Iacovone, Pierola and Rauch (2011) show that new export relationships from African countries (data from Malawi, Mali, Senegal, Tanzania) are more likely to last longer if there are other firms already exporting the same product, or to the same destination. However, these papers are about new export relationships, and only into the U.S. In contrast, we examine a broad set of countries, and do so over longer periods. Moreover, we focus on instability at the very top of the export distribution, which is where instability matters the most.

The most closely related paper to our work is Hanson, Lind and Muendler (2015). They use a gravity model to estimate source-country variation across industries, and find that the growth process underlying this variation over time exhibits mean-reversion and is consistent with a stationary distribution. Levchenko and Zhang (2011) compute industrylevel productivities in manufacturing and also estimate mean-reversion in industry productivities. Neither Hanson et al. (2015) nor Levchenko and Zhang (2011) address other sources of exporting variability. Another closely related paper is Gaubert and Itskhoki (2016), who study firm-level granular origins of comparative advantage. While the dynamic version of their model can mimic changes in industries' comparative advantage, they do not address the sources of firms' large productivity or demand shocks.

In contrast, our analysis of the sources of export growth variability includes all possible dimensions, including product-specific, as well as destinations. This is important: One of our main findings is that source-by-product (or industry) variation - the focus of 
Levchenko and Zhang (2011), Hanson et al. (2015) and Gaubert and Itskhoki (2016) - is not a large source of instability in exports over time. Destination-related (demand) factors matter more. ${ }^{10}$

\section{Data Description}

We obtain data on goods exported by over 100 countries from the United Nation's COMTRADE database. ${ }^{11}$ We use 4-digit (HS code) aggregation as a compromise between our interest in using well-defined categories of goods and the risk of measurement error, which increases due to the possibility of mis-classification as we disaggregate more. For each of these goods we have information on bilateral exports by year. Figure 5 shows that the sample of countries included each year is not constant. The sample increases constantly until the early 2000s and starts decreasing abruptly after 2010. Importantly, the selection of countries is not random as less developed countries are less likely to be present both in early and late years. Given these concerns, we focus our analysis on the years 1998 to 2010. Given our focus on medium-run trade growth, most of the analysis is performed using just the beginning and end points 1998 and 2010. We carry out robustness checks to test that our analysis is not biased by this selection.

\footnotetext{
10 Another difference between our work and Hanson et al. (2015) is that they use different industry classification, and in their main results they use only 133 industries, whereas our analysis utilizes about 1200 industries. This in itself can lead to different inferences.

11 The data is publicly available at http://comtrade.un.org/db/default.aspx.
} 


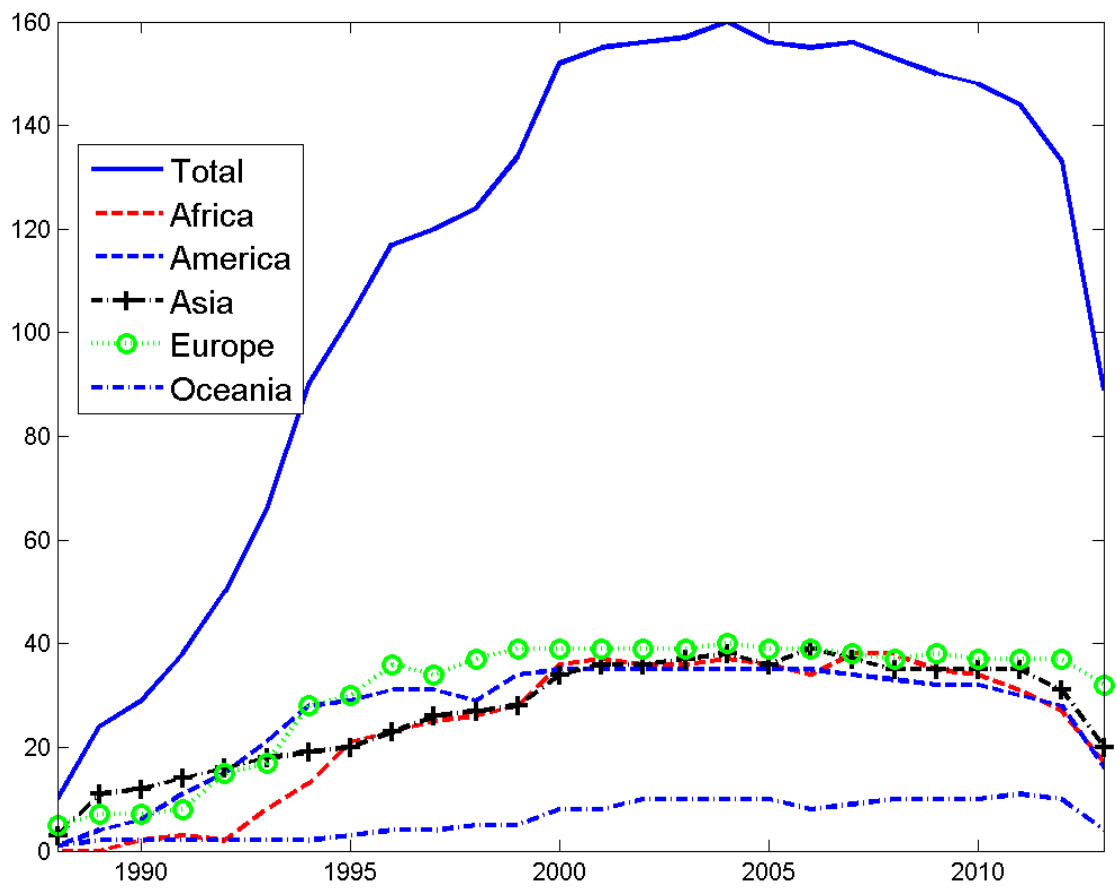

Figure 5: Number of countries sampled in COMTRADE per year, total and by continent.

Keeping only countries which have trade data on both 1998 and 2010 leaves a sample of 127 countries. We combine the trade data with information on real PPP GDP per capita from the Total Economy Database (TED) and transform all prices to constant 2012 US dollars using the CPI index from FRED. ${ }^{12}$ For some of our analysis we define two additional categories of goods - extractables and commodities - because of the (partly correct) belief that the poorest countries export mainly in these two categories. For this we use the reference suggested by the UN on the description of each the commodity list. The lists of goods included in each category are available in the appendix. For some of

12 For CPI we use the CPIAUCSL series from FRED, https://research.stlouisfed.org/fred2/, provided by the Federal Reserve Bank of Saint Louis. When using data on GDP per capita our sample is further reduced to 112 countries because TED does not report this information for 15 of the countries for which we have trade data. 
our analysis we classify countries according to their continents and their development level based on the list by the International Statistical Institute (ISI) and OECD. ${ }^{13}$

\section{Facts about Export Concentration and Instability}

In this section we show evidence on the degree of concentration in exports and, more importantly, the high instability within top exports. Section V will turn to characterizing the sources of this instability.

\section{A. Concentration of Exports}

In this section we show that the degree of concentration of exports is surprising for all countries. Table 1 shows that, on average, the single largest export category accounts for $25 \%$ of total exports. The top 20 exports account for almost $70 \%$ of total exports, and this figure is still extremely high even after excluding commodities and extractable goods. ${ }^{14}$

13 The list of developing countries is obtained from the ISI at http://www.isi-web.org/component/content/article/5root/root/81-developing. The list of OECD members is obtained from http://www.oecd.org/about/membersandpartners/.

${ }^{14}$ Table A1 in the appendix illustrates that African countries have more concentrated exports than OECD countries, on average. This relationship holds more generally: Higher income (GDP per capita in PPP units) is associated with lower shares of top 20 exported goods. 


\begin{tabular}{|c|c|c|c|c|c|c|}
\hline \multirow[b]{2}{*}{ Rank } & \multicolumn{3}{|c|}{ Export Shares: Goods (\%) } & \multicolumn{3}{|c|}{ Export Shares: Flows (\%) } \\
\hline & All Goods & Excl. Extractables & $\begin{array}{l}\text { Excl. Extractables } \\
\text { and Commodities }\end{array}$ & All Goods & Excl. Extractables & $\begin{array}{l}\text { Excl. Extractables } \\
\text { and Commodities }\end{array}$ \\
\hline 1 & 25.09 & 21.12 & 18.26 & 13.60 & 10.46 & 10.83 \\
\hline 2 & 10.57 & 9.57 & 9.24 & 6.52 & 5.62 & 5.25 \\
\hline 3 & 6.43 & 6.35 & 6.22 & 4.63 & 4.01 & 3.59 \\
\hline 4 & 4.55 & 4.39 & 4.49 & 3.34 & 2.95 & 2.81 \\
\hline 5 & 3.36 & 3.42 & 3.63 & 2.69 & 2.45 & 2.31 \\
\hline 6 & 2.69 & 2.80 & 2.99 & 2.21 & 2.02 & 1.95 \\
\hline 7 & 2.20 & 2.35 & 2.52 & 1.82 & 1.80 & 1.69 \\
\hline 8 & 1.88 & 2.06 & 2.17 & 1.59 & 1.55 & 1.49 \\
\hline 9 & 1.60 & 1.82 & 1.92 & 1.41 & 1.35 & 1.31 \\
\hline 10 & 1.43 & 1.60 & 1.71 & 1.24 & 1.21 & 1.20 \\
\hline 11 & 1.27 & 1.44 & 1.53 & 1.13 & 1.10 & 1.10 \\
\hline 12 & 1.16 & 1.32 & 1.41 & 1.02 & 1.02 & 1.03 \\
\hline 13 & 1.05 & 1.22 & 1.31 & 0.94 & 0.96 & 0.97 \\
\hline 14 & 0.97 & 1.12 & 1.20 & 0.87 & 0.90 & 0.92 \\
\hline 15 & 0.89 & 1.03 & 1.13 & 0.80 & 0.85 & 0.87 \\
\hline 16 & 0.83 & 0.97 & 1.06 & 0.75 & 0.80 & 0.82 \\
\hline 17 & 0.78 & 0.91 & 0.99 & 0.71 & 0.75 & 0.77 \\
\hline 18 & 0.73 & 0.85 & 0.93 & 0.67 & 0.72 & 0.73 \\
\hline 19 & 0.69 & 0.81 & 0.88 & 0.64 & 0.68 & 0.70 \\
\hline 20 & 0.65 & 0.78 & 0.85 & 0.60 & 0.65 & 0.66 \\
\hline Total & 68.85 & 65.92 & 64.45 & 47.17 & 41.85 & 40.99 \\
\hline & & & & & & \\
\hline Power Law 20 & -0.79 & -0.89 & -0.95 & -0.86 & -0.93 & -0.96 \\
\hline
\end{tabular}

Table 1: Export concentration among top 20 goods and flows, distribution within top 20 goods and flows, and power law coefficients. The table reports the average share of top 20 goods and flows (good-by-destination) for all countries in our sample at the 4-digit HS code level. Rankings are defined according to values in 2010. The power law coefficient is given by the regression of the log rank on the log export share. A lower coefficient in absolute value implies higher concentration. Source: COMTRADE.

The pattern of concentration within the top 20 exported goods can be captured by fitting a line to $\log$ ranks (vertical axis) and log export shares (horizontal axis). Such "power laws" are remarkably successful in describing concentration at the tails of the distribution of many economic (and other) phenomena (for example, see Newman 2005 and Gabaix 2016). This is true in our data as well. The last line in Table 1 reports the point estimate of the log rank regressed on log share across countries and groups of products. A smaller coefficient in absolute value implies higher concentration. These small coefficients, below unity in absolute value, indicate extremely high levels of 
concentration, that are only slightly larger in absolute value when excluding commodities and extractables. $^{15}$

We carry out the same analysis for what we call a "flow", defined as a particular product shipped to a particular destination, with very similar results. We illustrate this in the second set of columns in Table 1. Some differences are noticeable between the results that take into account the destination dimension and those that do not. First, the overall share of top 20 flows is smaller than for goods, which is to be expected. Second, concentration, as measured by the power law coefficient, is only slightly lower. These results are hardly affected when we exclude commodities and extractables. ${ }^{16}$

Table 2 correlates power law coefficients, which capture concentration at the top, with a few covariates of interest. ${ }^{17}$ The relationship between income and concentration within exports is systematic: Higher GDP per capita makes the power law coefficient more negative (i.e. increases it in absolute value), which implies lower concentration. When we include a GDP squared term (not reported), it is marginally significant at the 10 percent level. The implied turning point for $\log$ (GDPPC) is about 10, which is at the upper end of our sample range. Hence the negative relationship between GDP and the power law coefficient holds for most of our sample range. The squared term is not precisely estimated for the regressions using flows, which corroborates our conclusion that overall concentration is higher for less developed countries.

Power law coefficients also have a strong inverse relationship with the scale of total exports. The largest exporters are less concentrated at the top. Another important dimension is the total number of nonzero goods export categories (at the HS4 level) by

\footnotetext{
15

Power law coefficients less than one in absolute value (such as those in Africa) have the bizarre property that the mean of the underlying distribution is infinite. However, we are not claiming that the entire distribution fits a power law, only the tail of the top 20 categories.

${ }^{16}$ Table A2 in the appendix illustrates that the reduction in concentration when excluding commodities and extratables is much smaller for African countries versus OECD members. This illustrates another dimension of concentration: African exports are more concentrated across destinations within exported goods than OECD exports.

17 Helpman, Melitz and Yeaple (2004) also use power coefficients to capture concentration.
} 
exporter. This is the strongest predictor of power law variation: The steepest power laws are in countries that have many nonzero entries for different goods, implying that these exporters are less concentrated. When we examine concentration within top export flows (good-by-destination), the results are broadly similar to those for goods, but somewhat stronger.

\begin{tabular}{|c|c|c|c|c|c|c|}
\hline \multicolumn{7}{|c|}{ Dependent Variable: Power Law Coefficient } \\
\hline & \multicolumn{3}{|c|}{ Goods } & \multicolumn{3}{|c|}{ Flows } \\
\hline & (1) & (2) & (3) & (4) & (5) & (6) \\
\hline \multirow{2}{*}{$\ln (G D P p c)$} & $-0.0572 * *$ & & & $-0.111 * * *$ & & \\
\hline & $(0.0242)$ & & & $(0.0329)$ & & \\
\hline \multirow[t]{2}{*}{ In(Total Exports) } & & $-0.0395 * * *$ & & & $-0.0772 * * *$ & \\
\hline & & $(0.0123)$ & & & $(0.0160)$ & \\
\hline \multirow{2}{*}{ In(\# Goods Exp) } & & & $-0.295^{* * *}$ & & & $-0.187 * * *$ \\
\hline & & & $(0.0467)$ & & & $(0.0220)$ \\
\hline R-squared & 0.048 & 0.076 & 0.241 & 0.094 & 0.155 & 0.362 \\
\hline \# of countries & 127 & 127 & 127 & 127 & 127 & 127 \\
\hline
\end{tabular}

Table 2: Concentration across goods (4-digit HS codes), or flows (4-digit HS codes by destination) and development, total exports and the number of exported goods. The table reports OLS regressions of power law coefficients on log GDP per capita (in PPP units), log total exports, log number of goods exported. Data: COMTRADE, in 2010. Standard errors in parentheses. $* * * p<0.01, * * p<0.05$.

We further explore the degree of diversification of exports across destinations by summarizing concentration for the entire distribution. First, we calculate the Herfindahl index across destinations for each product exported from each country (higher index implies higher concentration). We then calculate the (trade value) weighted average of this index for each exporting country and year.

Figure 6 groups countries by their development stage. OECD countries are more diversified over destinations than African or other developing countries. ${ }^{18}$ Differences in

\footnotetext{
18 This is mainly driven by European countries' higher diversification. Figures that separate European countries from the rest are available upon request.
} 
concentration are very persistent: We do not observe strong trends in this measure of concentration, despite significant changes in income for most countries during this period. The jump in the early 1990s for Africa and other developing countries is due to changes in the sample, not within-country variation.

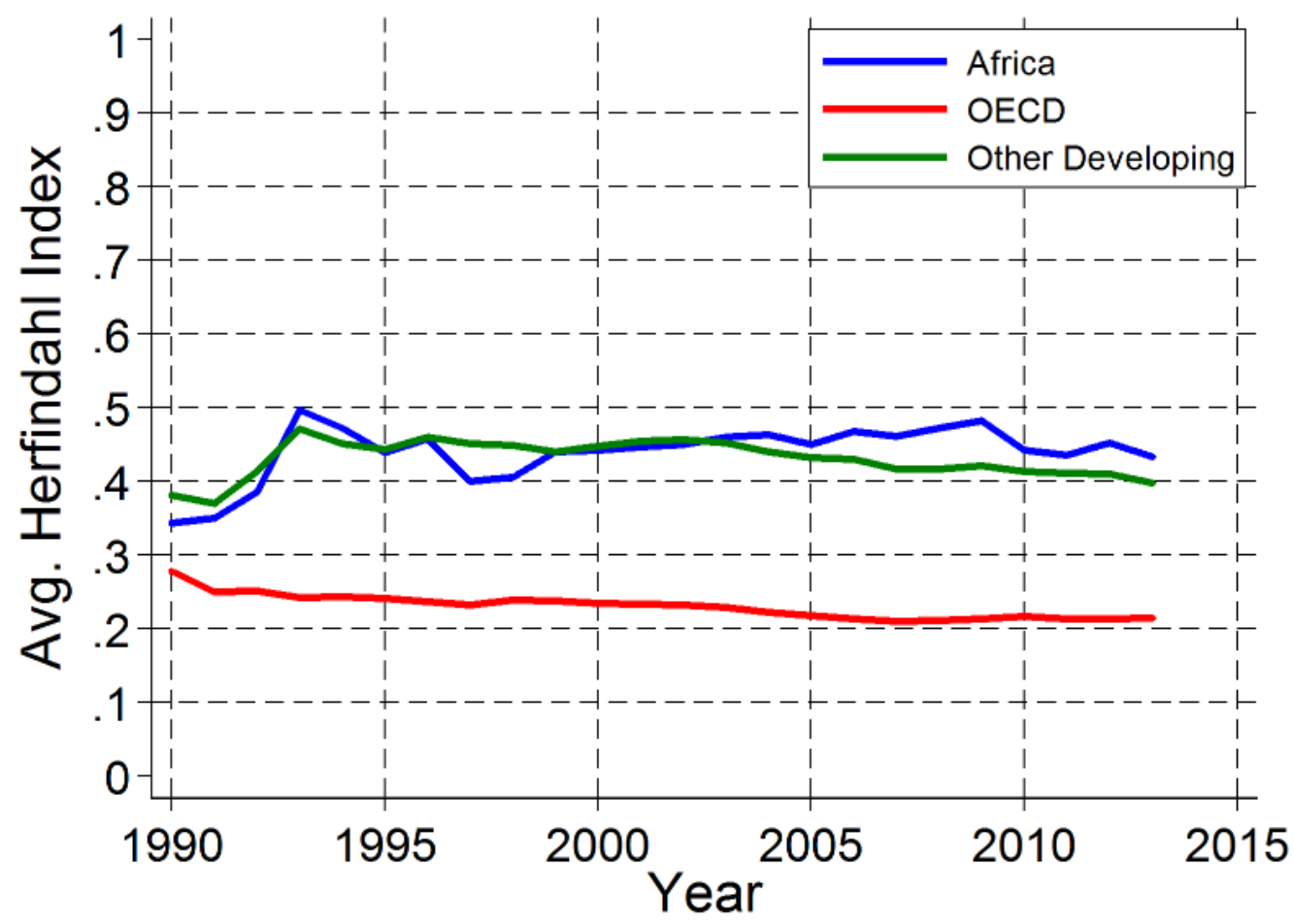

Figure 6: Weighted average of Herfindahl index over destinations for exports at the 4digit HS code level, where weights are volumes in 1998. The figure reports the average index for all countries' trading partners in each region. Source: COMTRADE.

When we regress our measure of concertation across destinations on log GDP per capita, we get a negative and highly statistically significant coefficient: Richer countries are more diversified. Similarly, when we regress concertation across destinations on log total exports, we get a negative and highly statistically significant coefficient: Countries that export more do so in a more diversified fashion. Finally, we find that European 
economies have more diversified exports across destinations relative to other economies. $^{19}$

In summary, all countries have surprisingly extreme power laws in top export products and top flows, but there is also variation among them. The steepest (most negative) slopes and least concentration are for countries that are in these (overlapping) categories: Higher income, higher total exports, and higher number of different goods exported. The destination specialization is also confirmed by surprisingly high Herfindahls by destination for the typical export product, although again the concentration is less for countries with higher income, more overall exports, and for European economies.

\section{B. Instability of Top Exports}

Our most interesting and novel finding is the instability of exports. In Figure 7 we illustrate this phenomenon for four countries: Tanzania, Ghana, Germany and The United States. ${ }^{20}$ For each country we rank the top 10 exported products (4-digit HS code) in 1998 and in 2010. Then, we show how the ranking of each top 10 export good changes from 1998 to 2010, and, vice versa, what the rank of each top 10 export good in 2010 was in 1998. Figure 7 illustrates the great extent of churning of ranks in export data; it also demonstrates that instability is pervasive, both in developed and developing countries. ${ }^{21}$

We address a concern that we could be exaggerating instability; perhaps there is just a lot of measurement error, such as misclassification of products over time. Figure 7 provides some reassurance that misclassification is not the primary factor in the results on instability. The replacement of former top goods by new ones generally features very different goods - they are generally not in adjacent categories that are likely to be subject

\footnotetext{
19 Regression results underlying these statements are available upon request.

20 In the appendix we report additional figures for Uganda and Japan.

${ }^{21}$ We do not report similar figures for top 20 products to ease the exposition, but these convey the same message.
} 
to reclassification from one to another. We address other types of measurement error below.

For example, in Tanzania (Figure 7-A), the top 3 exports in 1998 were nuts, coffee, and fish; these 3 shifted down to be \#6, \#7, and \#8 in 2010. Conversely, copper, manganese, and precious metal ore were virtually nonexistent exports in 1998, but by 2010 occupied the second through fourth ranks in Tanzanian exports. The new \#2 export, manganese, is a good example of concentration of destinations, as Tanzania's supplies went in 2010 only to China (65\%), Japan (23\%), and Germany (12\%). It is also an example of a strong product effect, as total trade in manganese vastly expanded from only $\$ 308$ million in 1998 to $\$ 4.2$ billion in 2010 .

In Ghana (Figure 7-B), the \#1 and \#2 exports in 1998, cocoa and gold, switched places, with a huge increase for gold. Aluminum plates in Ghana went from \#18 in 1998 to \#3 in 2010. Manganese had the same kind of increase in Ghana as it did in Tanzania, going from \$17 million to \$119 million from 1998 to 2010, but Ghana's top destination for this product was Ukraine instead of China.

Although we will show that there is somewhat less instability for higher income countries relative to poorer ones, it is still surprisingly high. In Germany (Figure 7-C), there is more stability in the top 4 , but \#5 (computers) declined to \#9 in 2010, \#6 (integrated circuits) went to \#16, and \#7 (motor vehicles for goods transport) declined to \#21. Those export ranks were replaced by "blood, antisera, vaccines, toxins and cultures" (\#91 to \#5), and printing machinery (\#12 to \#6).

The United States (Figure 7-D) illustrates even more instability than Germany. Aircraft was the top export in 1998 but fell to a rank of \#143 in 2010, while the related category of aircraft parts fell from \#7 to \#40. "Petroleum, bituminous, distillates, not including crude" rose from \#26 in 1998 to \#1 in 2010. Parts for office machines went from \#5 to $\# 15$, while "Medicaments, therapeutic, prophylactic use, in dosage" fell from \#26 to \#7. 
Goods that show a fall in more than one country (such as computers or integrated circuits, all falling in the US, Germany and Japan) or a rise (printing machinery in Germany and Japan) could be reflecting worldwide product trends, a possibility that our analysis below will allow us to address. 


\begin{tabular}{|c|c|c|c|c|}
\hline \multirow[b]{2}{*}{ Description } & \multicolumn{2}{|l|}{1998} & \multicolumn{2}{|l|}{2010} \\
\hline & Export Value & Rank & Export Value & Rank \\
\hline $\begin{array}{l}\text { Coconuts, Brazil nuts and } \\
\text { cashew nuts, fresh or dried }\end{array}$ & $\$ 150$ & 1 & $\$ 1,017$ & 1 \\
\hline $\begin{array}{l}\text { Coffee, coffee husks and skins } \\
\text { and coffee substitutes }\end{array}$ & $\$ 108$ & 2 & $\$ 486$ & 2 \\
\hline $\begin{array}{l}\text { Fish fillets, fish meat, mince } \\
\text { except liver, roe }\end{array}$ & $\$ 66$ & 3 & $\$ 376$ & 3 \\
\hline $\begin{array}{l}\text { Tobacco unmanufactured, } \\
\text { tobacco refuse }\end{array}$ & $\$ 61$ & 4 & $\$ 154$ & 4 \\
\hline $\begin{array}{l}\text { Gold, unwrought, semi- } \\
\text { manufactured, powder form }\end{array}$ & $\$ 55$ & 5 & $\$ 136$ & 5 \\
\hline Tea & $\$ 35$ & 6 & $\$ 133$ & 6 \\
\hline Cotton, not carded or combed & $\$ 33$ & 7 & $\$ 124$ & 7 \\
\hline $\begin{array}{l}\text { Cloves (whole fruit, cloves and } \\
\text { stems) }\end{array}$ & $\$ 30$ & 8 & $\$ 122$ & 8 \\
\hline Diamonds, not mounted or set & $\$ 29$ & 9 & $\$ 97$ & 9 \\
\hline $\begin{array}{l}\text { Mounted precious or semi- } \\
\text { precious stones, not diamonds }\end{array}$ & $\$ 20$ & 10 & $\$ 81$ & 10 \\
\hline & & & $\$ 76$ & 11 \\
\hline $\begin{array}{l}\text { Vegetables, leguminous dried, } \\
\text { shelled }\end{array}$ & $\$ 13$ & 13 & & \\
\hline & & & $\$ 50$ & 15 \\
\hline & & & $\$ 30$ & 20 \\
\hline & & & $\$ 9$ & 53 \\
\hline & & & $\$ 9$ & 58 \\
\hline $\begin{array}{l}\text { Copper, copper alloy, waste or } \\
\text { scrap }\end{array}$ & $\$ 0$ & 130 & & \\
\hline $\begin{array}{l}\text { Manganese ores, concentrates, } \\
\text { iron ores }>\mathbf{2 0} \% \text { Manganese }\end{array}$ & $\$ 0$ & 434 & & \\
\hline $\begin{array}{l}\text { Furnishing articles nes, except } \\
\text { mattresses, etc }\end{array}$ & $\$ 0$ & 683 & & \\
\hline $\begin{array}{l}\text { Precious metal ores and } \\
\text { concentrates }\end{array}$ & $\$ 0$ & 738 & & \\
\hline
\end{tabular}

Figure 7-A: Top exports churning in Tanzania. The figure reports the ranks and values of top ten exports in 1998 and in 2010, and their ranking and value in the opposite end of the sample, all in 2012 prices (thousands of U.S. dollars). Source: COMTRADE. 


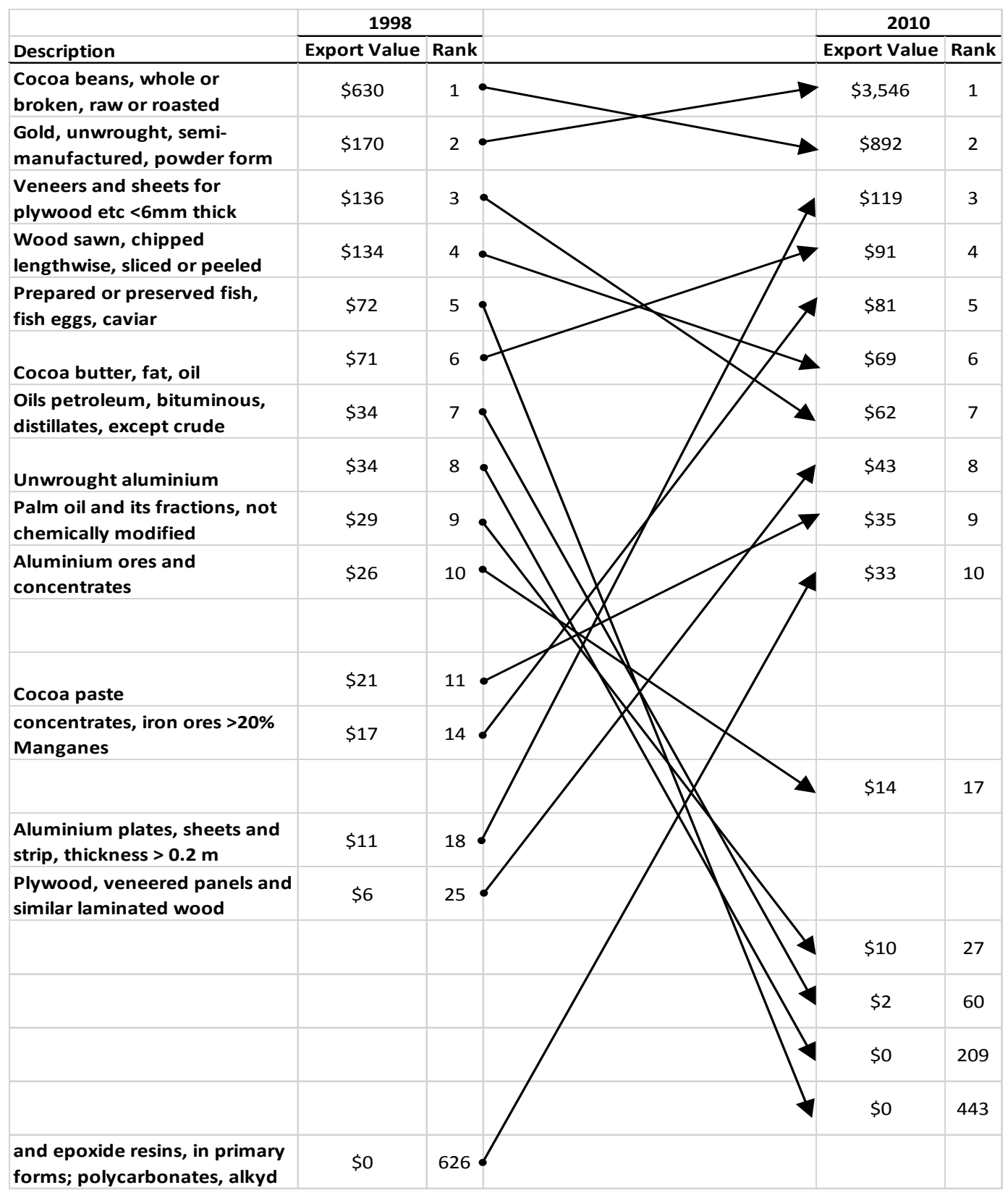

Figure 7-B: Top exports churning in Ghana. The figure reports the ranks and values of top ten exports in 1998 and in 2010, and their ranking and value in the opposite end of the sample, all in 2012 prices (thousands of U.S. dollars). Source: COMTRADE. 


\begin{tabular}{|c|c|c|c|c|}
\hline \multirow[b]{2}{*}{ Description } & \multicolumn{2}{|l|}{1998} & \multicolumn{2}{|l|}{2010} \\
\hline & Export Value & Rank & Export Value & Rank \\
\hline $\begin{array}{l}\text { Motor vehicles for transport } \\
\text { of persons (except buses) }\end{array}$ & $\$ 85,012$ & 1 & $\$ 135,467$ & 1 \\
\hline $\begin{array}{l}\text { Parts and accessories for } \\
\text { motor vehicles }\end{array}$ & $\$ 21,565$ & 2 & $\$ 46,211$ & 2 \\
\hline $\begin{array}{l}\text { Medicaments, therapeutic, } \\
\text { prophylactic use, in dosage }\end{array}$ & $\$ 13,786$ & 3 & $\$ 45,452$ & 3 \\
\hline Aircraft, spacecraft, satellites & $\$ 13,390$ & 4 & $\$ 24,386$ & 4 \\
\hline $\begin{array}{l}\text { Automatic data processing } \\
\text { machines (computers) }\end{array}$ & $\$ 12,312$ & 5 & $\$ 16,251$ & 5 \\
\hline $\begin{array}{l}\text { Electronic integrated circuits } \\
\text { and microassemblies }\end{array}$ & $\$ 8,924$ & 6 & $\$ 14,703$ & 6 \\
\hline $\begin{array}{l}\text { Motor vehicles for the } \\
\text { transport of goods }\end{array}$ & $\$ 8,476$ & 7 & $\$ 13,023$ & 7 \\
\hline $\begin{array}{l}\text { Electrical switches, } \\
\text { connectors, etc, for }<1 \mathrm{kV}\end{array}$ & $\$ 7,679$ & 8 & $\$ 12,719$ & 8 \\
\hline $\begin{array}{l}\text { Machines nes having } \\
\text { individual functions }\end{array}$ & $\$ 6,911$ & 9 & $\$ 12,695$ & 9 \\
\hline \multirow[t]{2}{*}{ Pumps for liquids } & $\$ 6,777$ & 10 & $\$ 11,746$ & 10 \\
\hline & & & $\$ 11,692$ & 11 \\
\hline $\begin{array}{l}\text { Printing and ancillary } \\
\text { machinery }\end{array}$ & $\$ 6,228$ & 12 & $\$ 11,361$ & 12 \\
\hline \multirow[t]{3}{*}{$\begin{array}{l}\text { Parts for internal combustion } \\
\text { spark ignition engines }\end{array}$} & $\$ 5,904$ & 13 & & \\
\hline & & & $\$ 10,568$ & 16 \\
\hline & & & $\$ 10,065$ & 18 \\
\hline \multirow[t]{2}{*}{$\begin{array}{l}\text { Instruments etc for medical, } \\
\text { surgical, dental, etc use }\end{array}$} & $\$ 5,016$ & 20 & & \\
\hline & & & $\$ 9,317$ & 21 \\
\hline $\begin{array}{l}\text { Oils petroleum, bituminous, } \\
\text { distillates, except crude }\end{array}$ & $\$ 3,438$ & 37 & & \\
\hline $\begin{array}{l}\text { Blood, antisera, vaccines, } \\
\text { toxins and cultures }\end{array}$ & $\$ 1,761$ & 91 & & \\
\hline
\end{tabular}

Figure 7-C: Top exports churning in Germany. The figure reports the ranks and values of top ten exports in 1998 and in 2010, and their ranking and value in the opposite end of the sample, all in 2012 prices (thousands of U.S. dollars). Source: COMTRADE. 


\begin{tabular}{|c|c|c|c|c|}
\hline \multirow[b]{2}{*}{ Description } & \multicolumn{2}{|l|}{1998} & \multicolumn{2}{|l|}{2010} \\
\hline & Export Value & Rank & Export Value & Rank \\
\hline Aircraft, spacecraft, satellites & $\$ 51,786$ & 1 & $\$ 56,545$ & 1 \\
\hline $\begin{array}{l}\text { Electronic integrated circuits } \\
\text { and microassemblies }\end{array}$ & $\$ 48,086$ & 2 & $\$ 41,373$ & 2 \\
\hline $\begin{array}{l}\text { Parts and accessories for } \\
\text { motor vehicles }\end{array}$ & $\$ 38,974$ & 3 & $\$ 39,553$ & 3 \\
\hline $\begin{array}{l}\text { Automatic data processing } \\
\text { machines (computers) }\end{array}$ & $\$ 36,388$ & 4 & $\$ 34,340$ & 4 \\
\hline $\begin{array}{l}\text { Parts, accessories, except } \\
\text { covers, for office machines }\end{array}$ & $\$ 27,779$ & 5 & $\$ 25,209$ & 5 \\
\hline $\begin{array}{l}\text { Motor vehicles for transport } \\
\text { of persons (except buses) }\end{array}$ & $\$ 23,526$ & 6 & $\$ 24,589$ & 6 \\
\hline $\begin{array}{l}\text { Parts of aircraft, spacecraft, } \\
\text { etc }\end{array}$ & $\$ 21,519$ & 7 & $\$ 24,355$ & 7 \\
\hline $\begin{array}{l}\text { propellers/other gas turbine } \\
\text { engines }\end{array}$ & $\$ 19,226$ & 8 & $\$ 23,166$ & 8 \\
\hline $\begin{array}{l}\text { Parts for use with lifting, } \\
\text { moving machinery }\end{array}$ & $\$ 12,510$ & 9 & $\$ 19,568$ & 9 \\
\hline $\begin{array}{l}\text { Electric apparatus for line } \\
\text { telephony, telegraphy }\end{array}$ & $\$ 11,701$ & 10 & $\$ 16,065$ & 10 \\
\hline $\begin{array}{l}\text { Instruments etc for medical, } \\
\text { surgical, dental, etc use }\end{array}$ & $\$ 11,546$ & 11 & & \\
\hline $\begin{array}{l}\text { Gold, unwrought, semi- } \\
\text { manufactured, powder form }\end{array}$ & $\$ 7,077$ & 15 & $\$ 13,010$ & 15 \\
\hline \multirow[t]{2}{*}{ Soya beans } & $\$ 6,880$ & 17 & & \\
\hline & & & $\$ 9,679$ & 21 \\
\hline $\begin{array}{l}\text { Oils petroleum, bituminous, } \\
\text { distillates, except crude }\end{array}$ & $\$ 5,622$ & 25 & & \\
\hline \multirow[t]{3}{*}{$\begin{array}{l}\text { Medicaments, therapeutic, } \\
\text { prophylactic use, in dosage }\end{array}$} & $\$ 5,501$ & 26 & & \\
\hline & & & $\$ 5,561$ & 40 \\
\hline & & & $\$ 1,876$ & 142 \\
\hline
\end{tabular}

Figure 7-D: Top exports churning in the United States. The figure reports the ranks and values of top ten exports in 1998 and in 2010, and their ranking and value in the opposite end of the sample, all in 2012 prices (thousands of U.S. dollars). Source: COMTRADE. 
Another way to show the instability of exports is to show the drastic changes in value over time. When ranks change, this is accompanied with huge swings in value. A log base 10 scale is necessary to capture these changes. Here a one-unit increase signifies an increase of 10 times; two units imply a change of 100 times. We do this for Ecuador in Figure 8-A and for Kenya in Figure 8-B.

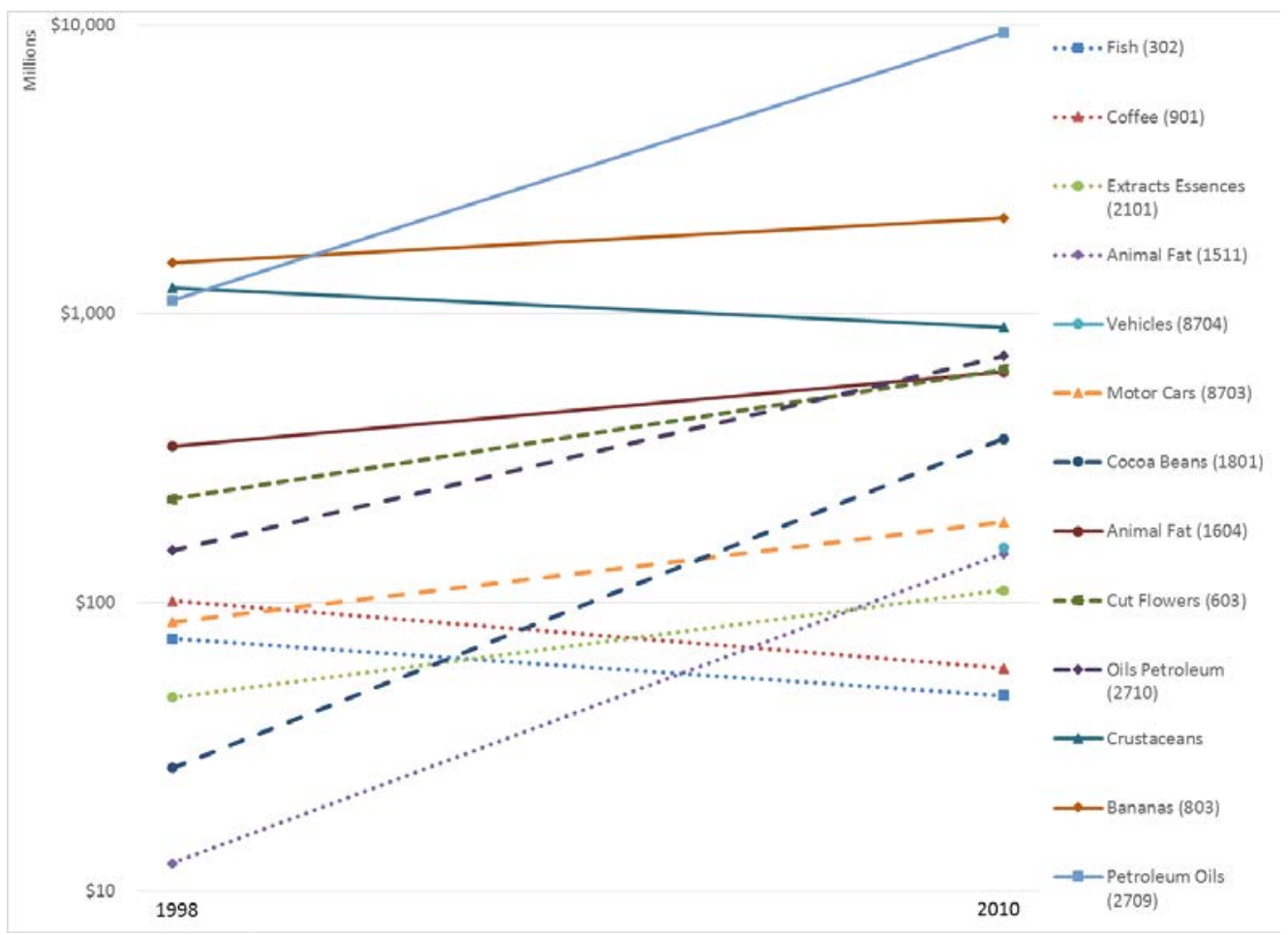

Figure 8-A: Ecuador top export revenues by good, log base 10 scale, 1998 and 2010. Source: COMTRADE.

Ecuador (Figure 8-A) shows an increase of a factor of 2.8 in cut flowers, while coffee export revenues fell by $40 \%$, which scrambled the ranks of top exports. In contrast, cocoa beans exhibited a 14 times increase in exports. Vehicles and parts thereof were not exported at all in 1998, but in 2010 they accounted for 155.4 million U.S. dollars (in 2012 prices). Even if this is partly related to the increase in exports of motor cars designed for the transport of persons - which increased by a factor of 2.2 - adding the two together 
indicates a large fourfold increase in the value of exports. Kenya in Figure 8-B shows the fall of a traditional export and the rise of some non-traditional ones. Coffee revenue declined 27 percent, while export revenue from cut flowers and fresh vegetables increased by a factor of 3.4. Exports of cement, another non-traditional export, increased almost threefold.

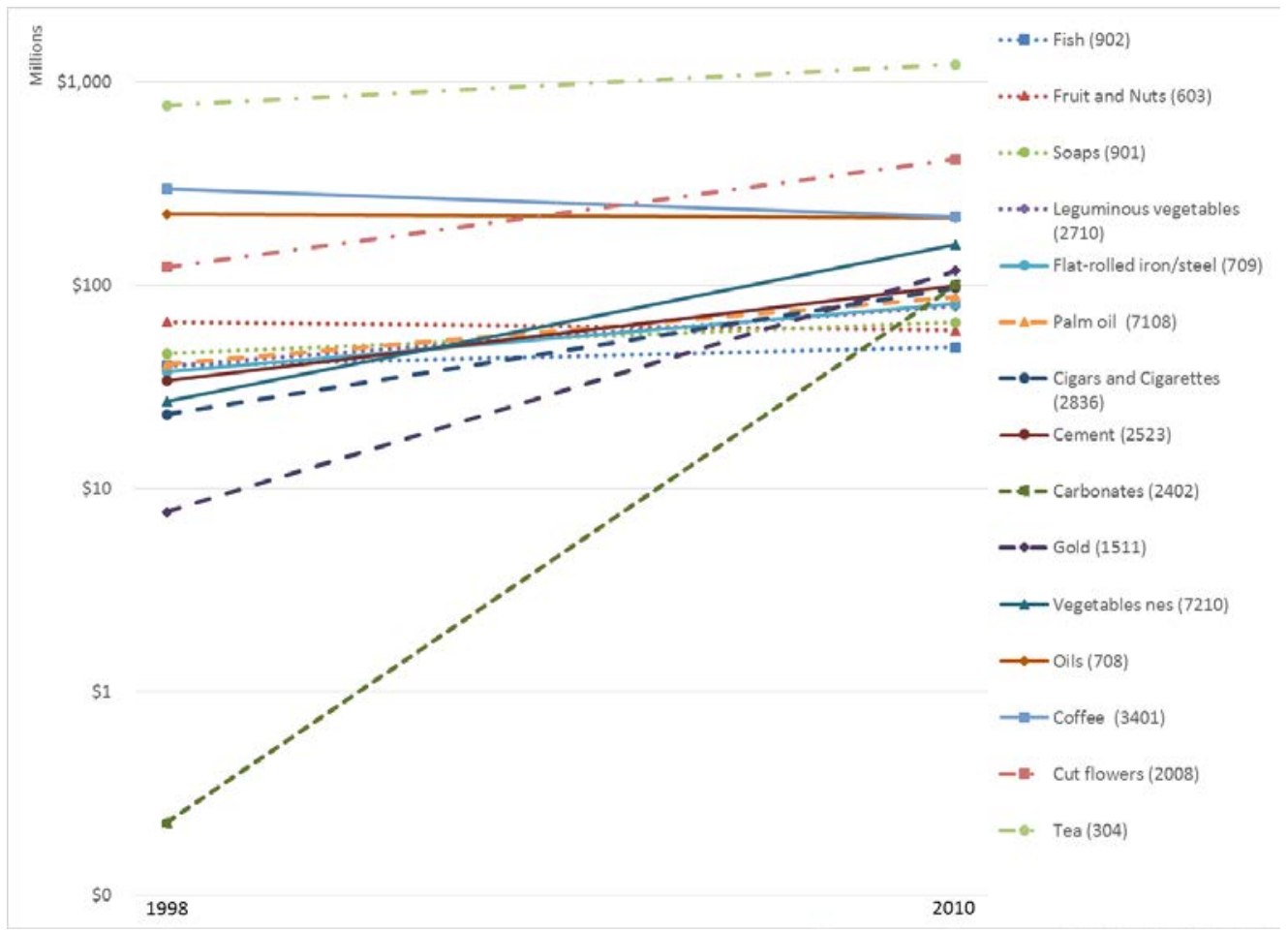

Figure 8-B: Kenya top export revenues by good, log base 10 scale, 1998 and 2010. Source: COMTRADE.

Cut flowers exports are a good example of the international dimensions of export performance. Table 3 shows the change in export revenue from cut flowers from 1998 to 2010 by source and destination (many smaller sources and destinations are omitted from the table to ease the exposition, but row and column totals include omitted countries). 
Change from 1998 to 2010 in Exports of Cut Flowers (million US\$ adjusted for inflation)

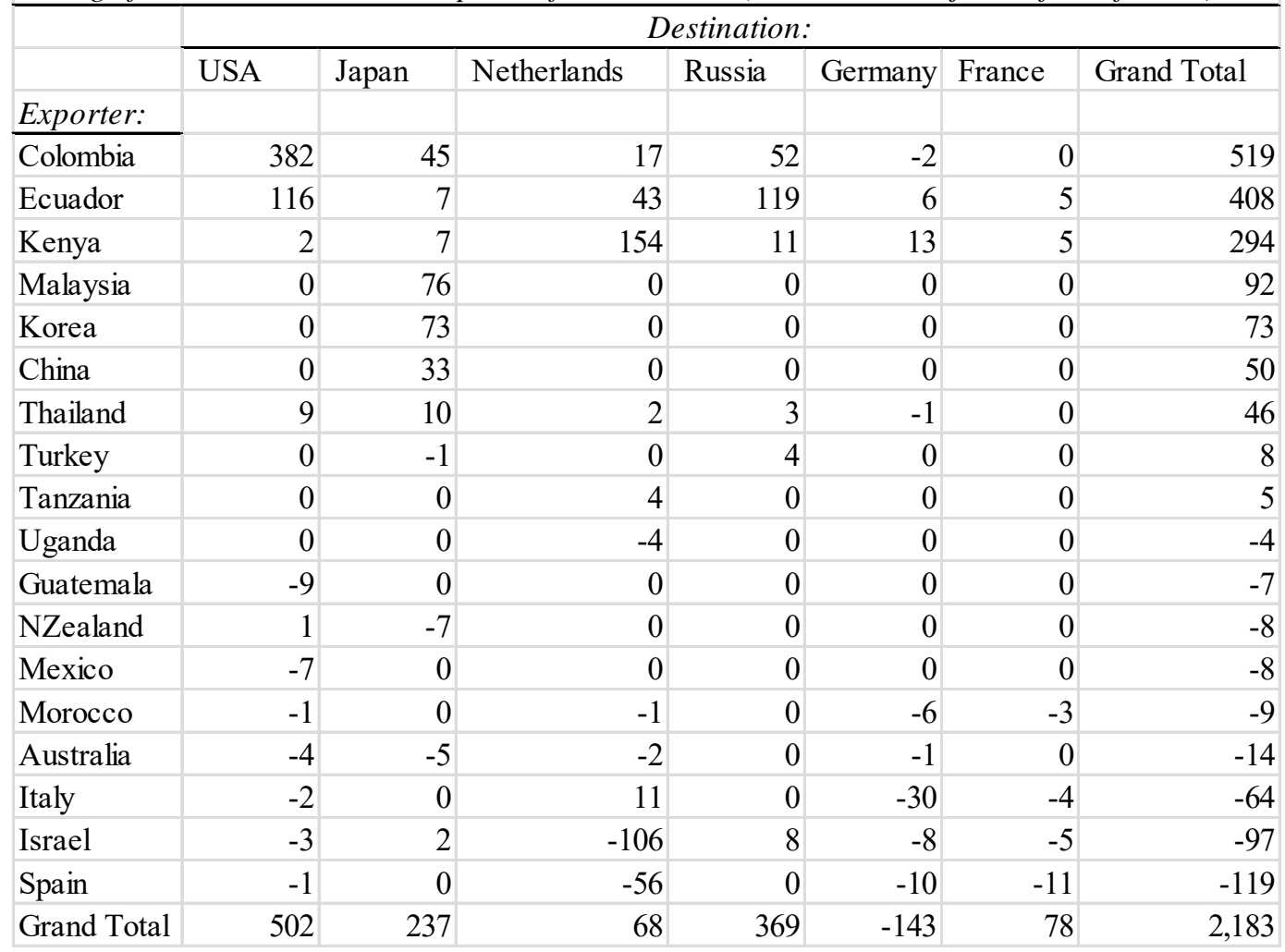

Table 3: Change in value of Cut Flowers Exports, millions of \$US. Source: COMTRADE.

Cut flowers trade as a whole grew by more than $\$ 2$ billion from 1998 to 2010 . The big winners are Colombia, Ecuador, and Kenya. Colombia and Ecuador presumably benefited from their closeness to the biggest growth market, the USA. They also managed to crowd out other nearby exporters like Mexico and Guatemala. Kenya did well by capturing more of the European market, which obviously reflects geographic distance again (although neighboring sources like Tanzania and Uganda failed to benefit). Malaysia, Korea, China, and Thailand in turn benefited from closeness to the Japanese growth market. The biggest losers were Australia and New Zealand for the Japanese market, and Italy, Israel, Morocco, and Spain for the European market. Italy and Morocco may have suffered in particular from the contraction of their previously large German market. There are some cross-overs between geographic markets, such as the surprising flow from Ecuador to Russia. This example shows the possibilities for source, 
destination, and product to interact in ways that we will explore formally in the last section - reinforcing the point that not everything in export performance is about source country characteristics or policies.

In Table 4 we draw a more systematic portrait of instability. For each country in our sample we rank the top exported goods (4-digit HS code) both in 1998 and 2010. We then keep only those goods that were among the top (for alternative cutoffs, i.e. top 10, top 20, top 50 and top 100) in 1998. If a good is not exported in 2010, we assign it a 2010 rank of $\mathrm{N}+1$, where $\mathrm{N}$ is the total number of goods exported in the corresponding country in 2010. Although not an ideal solution for disappearing products, it is not an issue for top 10 goods and top 20 goods, and rarely an issue otherwise, because if a top good is exported in 1998 it is almost always exported in 2010. We then compute the average across all countries of the Pearson correlation between ranks in 1998 and in $2010 .^{22}$ The average maximal number of goods that a country exports in 1998 is reported in the last column of Table 4.

Table 4-A illustrates the pervasiveness of instability of exported goods. Rank correlations are less than 0.3 for goods. The rank correlations are even lower when we exclude commodities and extractables, and focus on top 20 goods. Table 4-B reports similar patterns for flows (product-by-destination), although, not surprisingly, the magnitude of correlations is smaller. The upshot of Figure 7 and Table 4 is simple: Churning is pervasive, and particularly so within the top exported goods.

\begin{tabular}{|l|c|c|c|c|}
\hline & Top 20 & Top 50 & Top 100 & \# Goods \\
\hline All Goods & 0.271 & 0.259 & 0.292 & 831 \\
\hline Exclude Extractables & 0.276 & 0.27 & 0.302 & 697 \\
\hline Exclude Extractables and Commodities & 0.231 & 0.259 & 0.3 & 662 \\
\hline
\end{tabular}

Table 4-A: Rank correlations indicate great instability of top exported goods for all

\footnotetext{
22

22 This is equivalent to computing Spearman rank correlations between the values of goods that were ranked in 1998 and their values in 2010 .
} 
regions. The table reports the average across all countries of the correlation between ranks of top goods that were exported in 1998 and their ranks in 2010. See text above for more details. Data: COMTRADE.

\begin{tabular}{|c|c|c|c|c|}
\hline & Top 20 & Top 50 & Top 100 & $\begin{array}{c}\text { \# Goods- } \\
\text { Destinations }\end{array}$ \\
\hline All Goods & 0.107 & 0.078 & 0.096 & 15778 \\
\hline Exclude Extractables & 0.108 & 0.091 & 0.086 & 13992 \\
\hline Exclude Extractables and Commodities & 0.086 & 0.079 & 0.08 & 13613 \\
\hline
\end{tabular}

Table 4-B: Rank correlations indicate great instability of top exported flows (product-bydestination) for all regions. The table reports the average across all countries of the correlation between ranks of top flows that were exported in 1998 and their ranks in 2010. See text above for more details. Data: COMTRADE.

We now ask: Is the degree of instability and churning related to country characteristics? Using data on exports in 1998 and 2010 we define which goods belonged to either the top 10 or top 20 exports for each country-year. We estimate the probability that 1998 top goods remain at the top in 2010, looking at the relation with good and country characteristics. We estimate linear probability model regressions of the type

$$
\text { (1) } y_{g, c, 2010}=\alpha+\beta \cdot 1\left\{\text { Top }_{g, c, 1998}\right\}+\gamma \cdot X_{g, c} \cdot 1\left\{\text { Top }_{g, c, 1998}\right\}+\delta \cdot X_{g, c}+\mu_{g, c} \text {, }
$$

where $y_{g, c, t}=1\left\{\right.$ Top $\left._{g, c, t}\right\}$ is an indicator for good $g$ in country $c$ is a top good in year $t=$ 1998 or 2010, and $X_{g, c}$ stands for the characteristics of the good $g$ and country $c$ in 1998, which can be interacted with $1\left\{T o p_{g, c, 1998}\right\}{ }^{23}$ Since some of the right hand side regressors vary only by country (not by country and good), we cluster standard errors by country (Moulton, 1990). We report descriptive statistics and correlations in the appendix.

\footnotetext{
${ }^{23}$ We also estimated corresponding probit models, with similar results, which are available upon request.
} 
Table 5 shows that without conditioning on any other information, the probability of remaining a top 20 good is around 0.54 , a small probability in itself, which indicates the high degree of churning into and out of the top 20 group. Column 2 shows that overall, goods exported from richer countries have a lower probability to be in the top 20, by virtue of these countries exporting more products. ${ }^{24}$ But the probability of remaining a top 20 good - conditional on being a top 20 good in 1998 - is increasing in the level of GDP per capita of the country: Richer countries exhibit less instability. ${ }^{25}$ Figure 9 illustrates that this result also holds when we look at flows (goods-by-destinations) rather than goods.

\begin{tabular}{|c|c|c|c|}
\hline & (1) & $(2)$ & (3) \\
\hline \multirow[t]{2}{*}{ Top in Start Year } & $0.540 * * *$ & 0.0679 & $0.364 * * *$ \\
\hline & $(0.0142)$ & $(0.0836)$ & $(0.106)$ \\
\hline \multirow[t]{2}{*}{$\ln ($ Initial GDPpc) } & & $-0.00289 * * *$ & $-0.00420 * * *$ \\
\hline & & $(0.000407)$ & $(0.000593)$ \\
\hline \multirow[t]{2}{*}{ In(Initial GDPpc) x Top in Start Year } & & $0.0529 * * *$ & $0.0309 * * *$ \\
\hline & & $(0.00914)$ & $(0.0106)$ \\
\hline \multirow[t]{2}{*}{ Initial Herfindahl Index over Destinations } & & & $-0.0129 * * *$ \\
\hline & & & $(0.00153)$ \\
\hline \multirow[t]{2}{*}{ Initial Herfindahl Index over Destinations x Top in Start Year } & & & $-0.276 * * *$ \\
\hline & & & $(0.0468)$ \\
\hline \multirow[t]{2}{*}{ Constant } & $0.00907^{* * *}$ & $0.0358 * * *$ & $0.0545^{* * *}$ \\
\hline & $(0.000433)$ & $(0.00396)$ & $(0.00622)$ \\
\hline Observations & 104,533 & 90,317 & 90,317 \\
\hline R-squared & 0.29 & 0.31 & 0.32 \\
\hline Number of countries & 103 & 103 & 103 \\
\hline
\end{tabular}

Table 5: Probability of being in the top 20 goods in 2010, marginal effects. "Top Start Year" takes value one if the good was top 20 in 1998. See text above for more details. Standard errors clustered by country in parentheses. ${ }^{* * *} p<0.01, * * p<0.05, * p<0.1$. Data: COMTRADE.

\footnotetext{
24 This is not inconsistent with Fernandes, Freund and Pierola (2016), who illustrate that the intensive margin within firms is more important for determining concentration than the extensive margin across firms. Since multiproduct firms are more prevalent in rich countries, their findings are consistent with the extensive margin across products being more important for determining concentration in rich versus poor countries.

25 This is consistent with results in Fernandes, Freund and Pierola (2016), who find greater instability (entry and exit) at the firm level in developing countries.
} 
In column 3 of Table 5 we add controls for concentration: The Herfindahl Index over Destinations for each product exported from each source exporting country. Higher concentration across destinations reduces the probability of a good to be in the top: Goods that are exported more evenly and to more destinations are more likely to be a top good. Higher concentration across destinations also reduces chances of remaining a top 20 good: Top goods that are exported more evenly and to more destinations are more likely to remain a top good. This result is significant, because it indicates the importance of destination-specific factors in determining instability, and we investigate this relationship further below. As we saw above, richer (OECD) countries are less concentrated by destination, and this can help explain part of the relationship of instability with income, as the coefficient to $\ln$ (Initial GDP per capita) x Top in Start Year drops by $40 \%$. This is also evident in the correlations table in the appendix. 


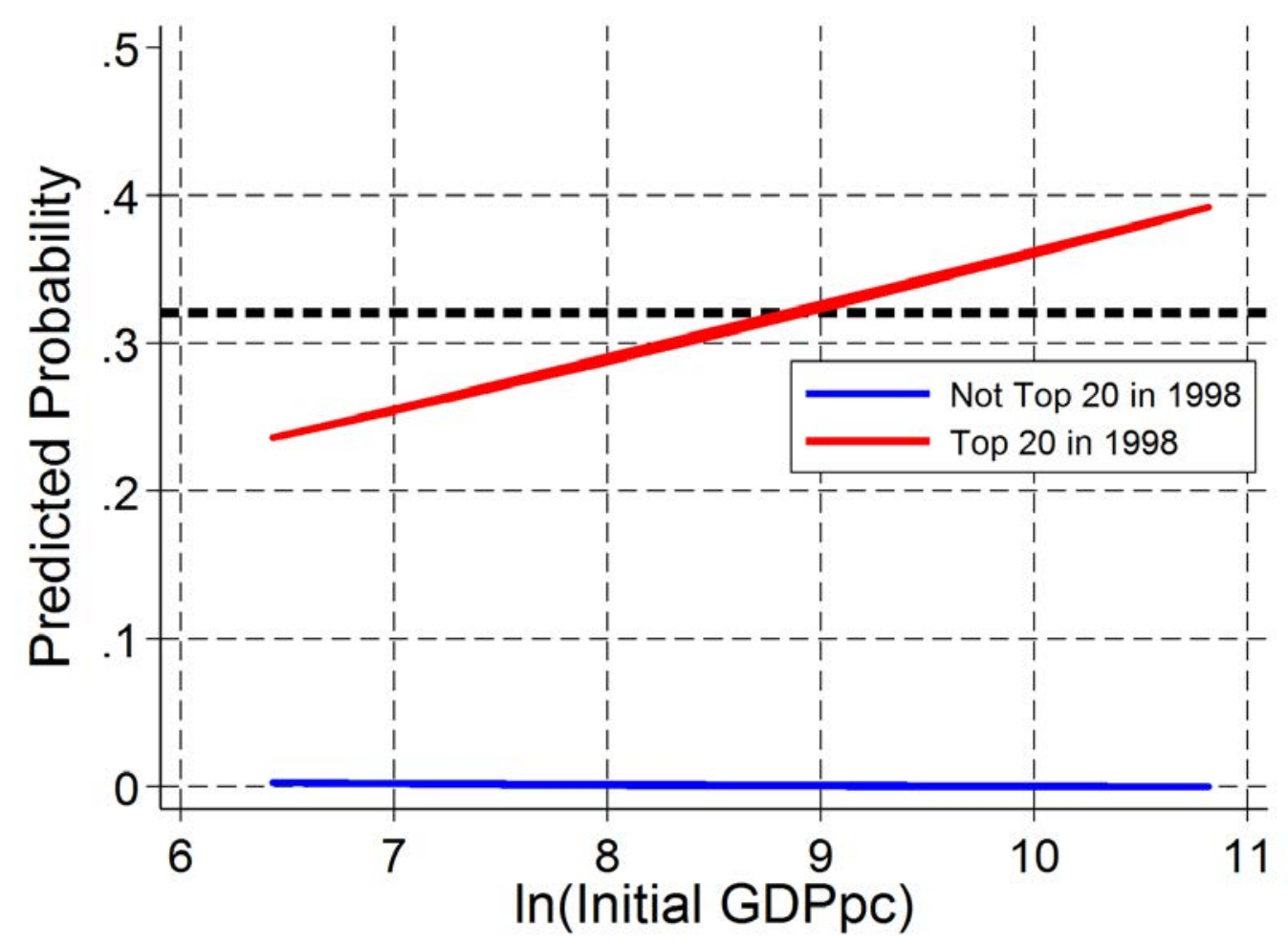

Figure 9: Marginal Effects of GDP per Capita on Persistence of Top 20 Export Flows. The figure reports the predicted probability of being a top 20 flow in 2010 for flows that were $($ Top0 = 1) and were not (Top0 = 0) top 20 in 1998. The dashed line is the unconditional probability of a top 20 flow in 1998 of being a top 20 flow in 2010. See text above for more details. Data: COMTRADE.

Next, we check that our selection of years is not driving our results. We perform a similar analysis while allowing either initial or end years to change. First, we fix the initial year 1998 and look at the probability of remaining top goods in each year from 1999 to 2010. Then we estimate the reverse probability that goods that are top in 2010 were also among the top in the previous years. These regressions also serve as a test on the risk of measurement error in the data. If measurement error explains our results, we would expect that the probability estimates to fluctuate erratically with no trend over 
time. They actually show a smooth trend, which is more consistent with gradual entry of new products and exit of old ones.

We first fit following linear probability models of the following form

$$
\text { (2) } y_{g, c, t}=\alpha+\beta_{t} \cdot 1\left\{\operatorname{Top}_{g, c, 1998}\right\}+\mu_{g, c, t} \text {, }
$$

where $\beta_{t}$ is the coefficient of interest, $t=1999,2000, \ldots 2010$. Figure 10 reports the sequence of $\beta_{t}$ 's, (which are all precisely estimated) which are the probabilities of being a top 20 good in year $t$, conditional on being a top good in 1998. The decline in the probability of being in the top 20 goods is smooth, which suggests that measurement error is not solely driving our results.

Figure 10 also illustrates that persistence in Africa (as a simple way to capture low income countries) is lower than in the OECD countries, and that this is true over all horizons. A similar figure for the probability of being in the top 20 goods in 2010 conditional on being top in year $t=2009,2008$...1998 delivers a similar message (and is available upon request). 


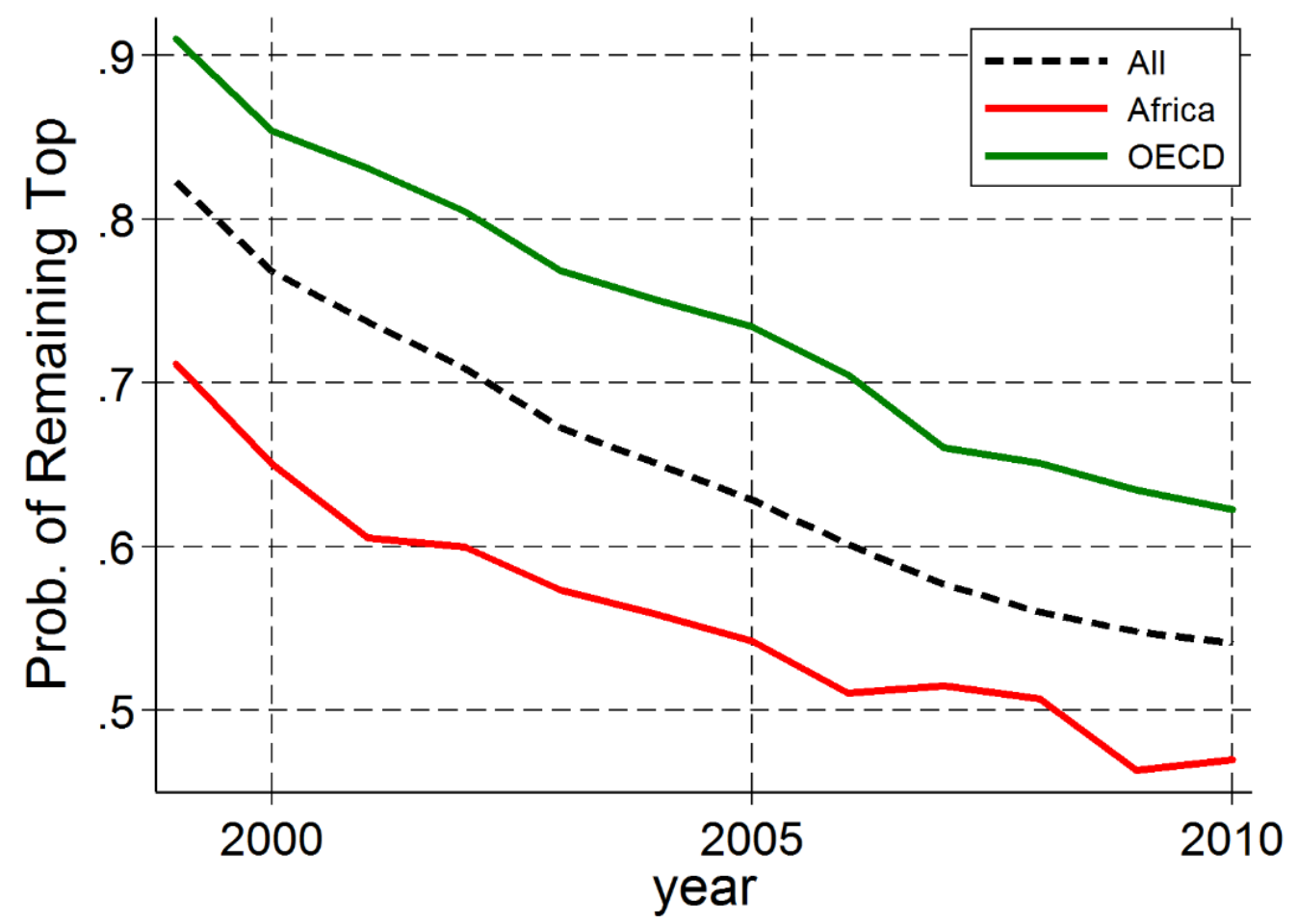

Figure 10: The figure reports the predicted probability of being a top 20 good in each year conditional on being a top 20 good in 1998. See text above for more details. Data: COMTRADE.

Figure 11 reports the coefficient to the interaction of income with being a top export good in 1998, $\gamma_{t}$, which captures the differential effect of income on persistence:

$$
\text { (3) } \begin{aligned}
y_{g, c, t}= & \alpha+\beta_{t} \cdot 1\left\{\text { Top }_{g, c, 1998}\right\}+\gamma_{t} \cdot 1\left\{\text { Top }_{g, c, 1998}\right\} \cdot \log (\text { GDP per capita })+ \\
& +\delta_{t} \cdot \log (\text { GDP per capita })+\mu_{g, c, t}
\end{aligned}
$$

The effect is always positive (and always precisely estimated), and remains similar for all time difference lengths, despite a weak overall downward trend. This implies that richer countries exhibit greater persistence of goods in the top, and that this effect is always positive and relatively stable, regardless of the time horizon. 


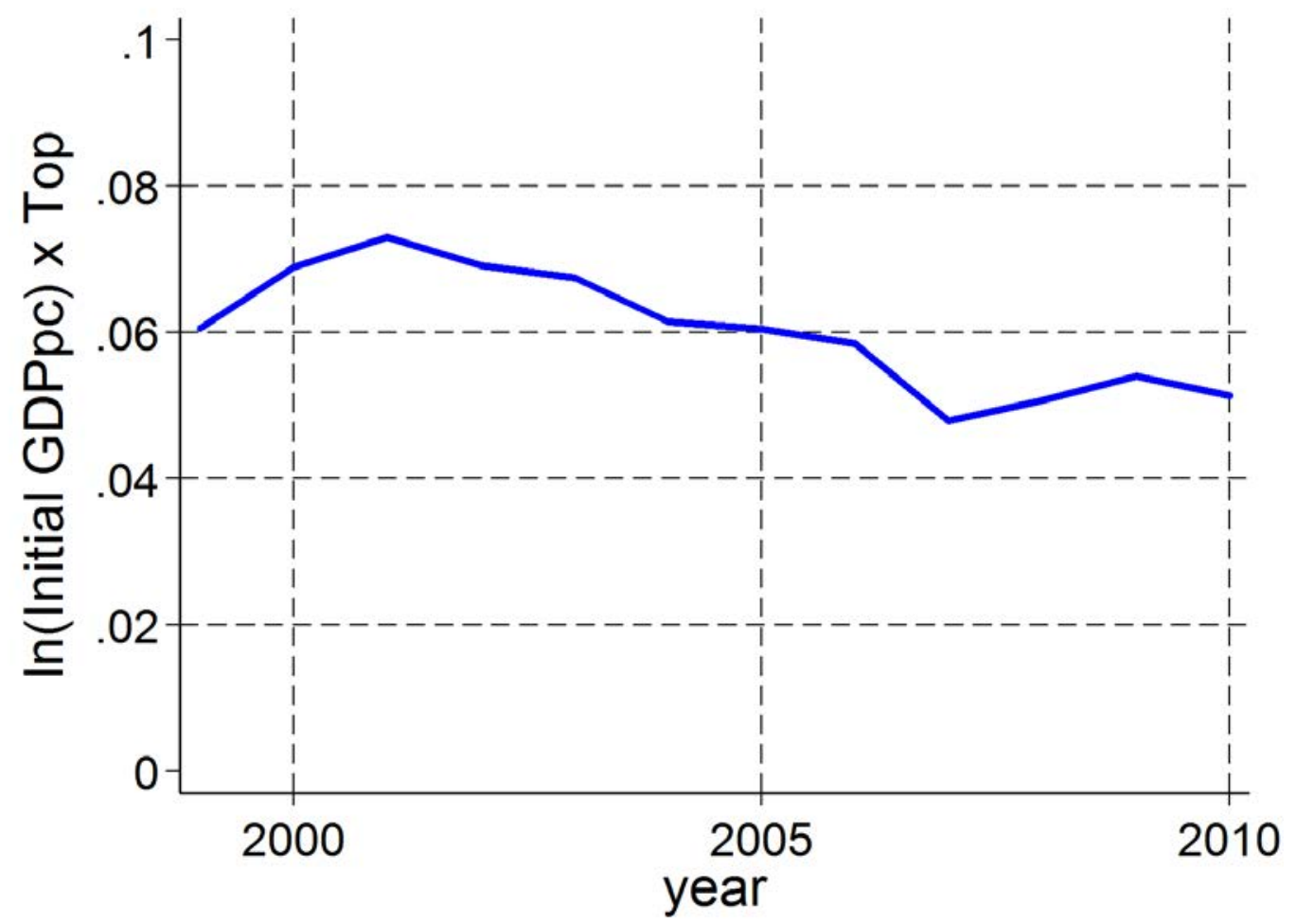

Figure 11: Linear probability model, marginal effect of GDP on probability of remaining top good over time (Top 20, Goods). The figure reports the marginal effect of GDP on the predicted probability of being a top 20 good in 2010 for goods that were top 20 in 1998. See text above for more details. Data: COMTRADE.

We now ask: Is having more instability of top exports associated with worse export growth performance? We estimate specifications like equation (2), where we differentiate by high, medium and low export growth. Here "high" is defined as being at or above the 75th percentile of export growth, "medium" as being between 25th and 75th percentiles, and "low" as being at or below the 25 th percentile. In Figure 12 we find that a higher exit 
rate out of the top 20 goods for countries with more rapid overall export growth, and this difference becomes larger with longer horizons. ${ }^{26}$

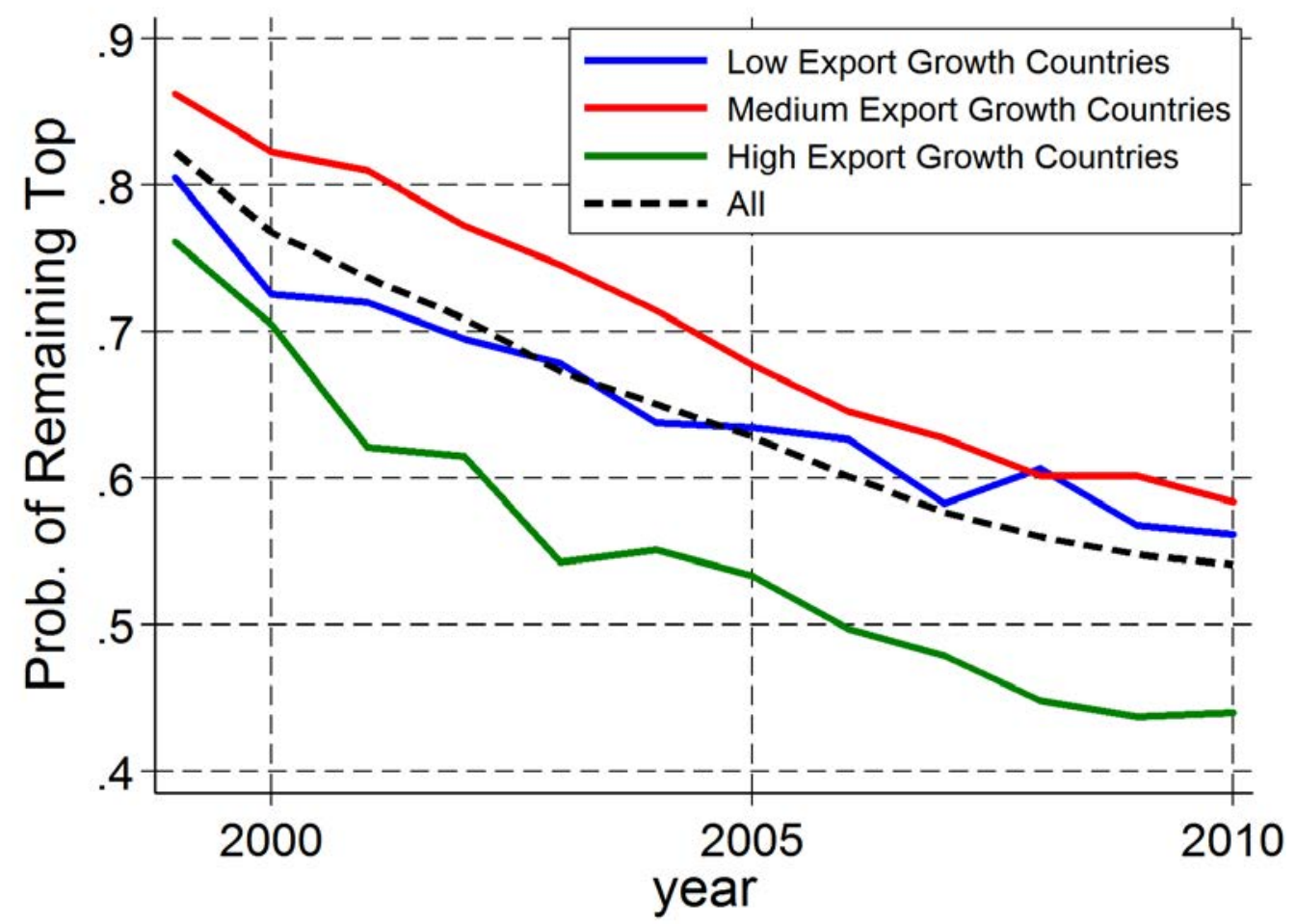

Figure 12: Linear probability model, probability of remaining top good over time by Total Export Growth (Top 20, Goods). The figure reports the probability of being a top 20 good in each year for goods that were top 20 in 1998 for different groups of countries according to their total export growth between 1998 and the year in the horizontal axis. Here "high" is defined as being at or above the 75th percentile of export growth, "medium" as being between 25th and 75th percentiles, and "low" as being at or below the 25th percentile. Data: COMTRADE.

${ }^{26}$ We focus on top 20 goods, but results are similar if using top 10 goods or flows; these results are available upon request. When we go in the opposite direction, the message is on instability is the same: goods that were in the top 20 category in 2010 have a differentially smaller chance of being in that category in earlier years for high export growth countries. This figure is available upon request. 
In conclusion, this section presented the key finding of the paper - that instability of top exports is surprisingly high for all countries. The probability of remaining in the top exports falls smoothly with time, which suggests that simple i.i.d. measurement error is not solely driving the results. Across countries, instability is higher along the same splits featured in the previous section: low income vs. high income, Africa vs. OECD, and high export growth vs. low export growth.

\section{Sources of Instability}

So far we have illustrated the great degree of concentration in exports, and the instability within top exports. We now turn to characterizing the sources of this instability. A better accounting of the underlying sources of instability can inform theory and policy alike.

At the most basic level we can characterize an export flow along these dimensions:

(i) Exporter (source country) characteristics (absolute advantage due to infrastructure, export barriers, aggregate productivity, etc.);

(ii) Importer (destination country) characteristics (wealth or income level, import barriers, etc.);

(iii) Products (quality, world taste or demand, etc.).

We extend this to include the following interactions:

(iv) Source-product characteristics (comparative advantage: distribution of productivity across goods in exporter country, and other cost-driven product variation, etc.);

(v) Destination-product characteristics (taste for particular good in destination, productivity of good as an input at the destination, particular import barriers for specific product in importer country, etc.);

(vi) Source-destination bilateral characteristics (distance, trade relations, etc.). 
We describe the importance of each of these dimensions in accounting for variation in trade flow growth. We do this in a non-parametric way, by studying the importance of each dimension using the variance (and covariance) share of fixed effects in the total variance.

The estimation framework starts from a gravity-inspired equation for log exports $x$ from source $s$ to destination $d$ of product $p$ in time $t$,

$$
\text { (4) } x_{s d p t}=\alpha_{t}+\theta_{s t}+\vartheta_{s p t}+\beta_{s d t}+\gamma_{p t}+\delta_{d t}+\rho_{d p t}+\varepsilon_{s d p t}
$$

where $\alpha_{t}$ captures a global aggregate trend in total trade; $\theta_{s t}$ captures the aggregate productivity (absolute advantage) in source country $s$ in time $t ; \vartheta_{s p t}$ captures the comparative advantage of source country $s$ in product $p$ in time $t ; \beta_{s d t}$ captures the bilateral factors that affect exporting from $s$ to destination country $d$ in time $t ; \gamma_{p t}$ captures global demand for product $p$ in time $t ; \delta_{d t}$ captures the aggregate demand in destination country $d$ in time $t ; \rho_{d p t}$ captures the relative demand in destination $d$ for product $p$ in time $t$; and $\varepsilon_{s d p t}$ is the residual which may reflect source-destination-product specific demand or supply shocks over time. ${ }^{27}$ Taking first differences of (4) from 1998 to 2010 we have

$$
\text { (5) } x_{s d p}=\alpha+\theta_{s}+\vartheta_{s p}+\beta_{s d}+\gamma_{p}+\delta_{d}+\rho_{d p}+\varepsilon_{s d p} \text {, }
$$

where a variable without time subscript is in changes, e.g., $\alpha=\alpha_{2010}-\alpha_{1998}$. We estimate (5) by exploiting the variation in exports flows of different products across sources and destinations.

\footnotetext{
27 Each of these components can be characterized in a gravity model. However, this representation ignores the concept of "structural gravity", e.g., the inter-linkages between source and destination fixed effects.
} 
In order to avoid losing observations that either end or start with zero exports, we replace log differences on the left hand side of (5) with bounded growth

(6) $\quad x_{s d p}=\frac{x_{s d p, 2010}-x_{s d p, 1998}}{\frac{1}{2}\left(x_{s d p, 2010}+x_{s d p, 1998)}\right.}$,

which has the virtue of explicitly taking into account new goods that emerge, as well as old goods that disappear. That is, we take into account $x_{s d p, t}$ export values that are zero.

Estimating (7) using all countries at once is not feasible given the computation power available to us. Therefore, we estimate (7) separately for each country and then recover the estimates in (7) by computing the appropriate averages and computing the deviations of the original estimates from averages. See the appendix for complete details on this.

After estimating the fixed effects (FE), we describe the results for the average country in the sample. To do this, we first compute the share in total variance of each type of FE, covariance and residuals, separately for each country; then we compute the average share for the average country. In the appendix we report results for average countries across regional subsamples and degrees of export growth. We estimate fixed effects and evaluate the sources of export growth twice: Once for top 20 exports (defined either in 1998 or 2010), and for all exports. This is informative because it allows us to see whether the sources of export growth are materially different for top 20 exports versus the rest. Then we repeat the estimation in a sample that takes into account only strictly positive flows in 1998 and 2010, i.e. eliminating new and disappearing export flows. This serves as a sensitivity analysis to the use of bounded growth.

Table 6 reports the results. The first row reports the average standard deviation of bounded growth for each sample. This number can be compared to 4 , which is the range of bounded growth. Unsurprisingly, it is lower when we exclude new and disappearing flows. There is some variation across subsamples, but the broad message is similar: 
variation in export growth for top 20 goods is driven by all dimensions. The single largest dimension is the residual, accounting for about one-third or one half of overall variance.

\begin{tabular}{|c|c|c|c|c|}
\hline \multirow[b]{2}{*}{ Sample: } & \multirow[b]{2}{*}{ Top 20 Flows } & \multirow[b]{2}{*}{ All Flows } & \multicolumn{2}{|c|}{ Strictly positive flows in 1998 and 2010} \\
\hline & & & Top 20 Flows & All Flows \\
\hline Standard deviation & 1.62 & 1.67 & 1.30 & 1.34 \\
\hline \multicolumn{5}{|l|}{ Perecent of overall variance } \\
\hline Source $x$ Product & 19 & 18 & 31 & 31 \\
\hline Source $x$ Destination & 18 & 11 & 21 & 9 \\
\hline Product & 12 & 4 & 19 & 5 \\
\hline Destination & 11 & 11 & 3 & 2 \\
\hline Destination $\mathrm{x}$ Product & 19 & 6 & 22 & 10 \\
\hline Residual & 34 & 50 & 33 & 50 \\
\hline $2 \times \operatorname{Cov}$ (Product, Source $\times$ Product) & -12 & -1 & -23 & -1 \\
\hline
\end{tabular}

Table 6. Variance decompositions of export growth of export flows in 1998-2010 for the average country. There are four subsamples: top 20 exports, all export flows, and the same while restricting to strictly positive export flows in both 1998 and 2010. Columns do not sum exactly to 100 because other covariance terms are not reported here; these covariance terms account for small shares of overall variance. Data: COMTRADE.

The key result in Table 6 is that variation in comparative advantage (Source $\mathrm{x}$ Product) accounts for only $18-19 \%$ of overall variation in export growth, or $31 \%$ when we do not consider new and disappearing flows. Thus, variation in comparative advantage is relatively less important for new and disappearing export flows; other sources of variation are more important for these products. The role of comparative advantage by itself (Source x Product) is smaller than we expected. This suggests that theories of export success that focus only on comparative advantage (and the policies motivated by such stories) may be missing much of the origins of export success. It is particularly telling that these results are similar for countries with high, medium and low total export growth, and across different regions (results reported in the appendix).

In general, whether or not we consider new and disappearing flows, the following factors are more important for top 20 exports: Variation in bilateral conditions (Source $\mathrm{x}$ 
Destination), destination demand for specific products (Product $\mathrm{x}$ Destination), and variation in aggregate demand for product. Not surprisingly, the residual becomes much more important outside of the top 20 exports and picks up most of the difference. Aggregate demand from the destination accounts for $11 \%$ of the variance, but only $2-3 \%$ when we ignore new and disappearing flows.

It is notable that the global product, destination and Destination $\mathrm{x}$ Product interaction effects, together account for a similar share of overall variation as the sum of effects involving the source country, Source x Product and Source x Destination, even though the latter does not capture strictly only source country effects - except when we consider all flows and exclude new and disappearing flows. While we cannot rigorously use this decomposition to locate the micro origins of the shocks driving export flows, these results suggest that a lot of action in exports is not driven by source country factors alone. The upshot is that perhaps too much export success or failure is attributed to the source countries as opposed to demand effects coming from outside the source country. This helps us understand why specializations are so unstable - they are at the mercy of demand effects coming from many different sources.

The variance decomposition involves also covariance terms between different sources of export growth. Table 6 reports the only one that is of significant magnitude, Cov(Product, Source x Product), and only when we restrict to top 20 exports. All other covariance terms are very small, and many are virtually zero (all are reported in the appendix). ${ }^{28}$

We draw a few conclusions from this part of our analysis. First, trade models that rely only on variation in comparative advantage, bilateral forces and destination income 28 We test whether variance shares correlate with income per capita and concentration. We find that Comparative
advantage (Source x Product) and bilateral forces (Source x Destination) account for less of overall variance for richer
countries and with more diversified countries. These results are reported in the appendix. However, since these are shares
within overall variance, it is difficult to relate these to the stability regressions reported in Table 5 . 
e.g., Eaton and Kortum (2002) at the aggregate level - are insufficient for explaining export growth at the more granular level. Adding demand shocks is necessary, as Eaton, Kortum and Kramarz (2011) illustrate at the firm level. This is consistent with Gaubert and Itskhoki (2016), who find that granular firm-level shocks are important for understanding industry-level comparative advantage. Here we investigate the potential sources of these shocks, and we find that much of the variation originates outside of the exporting-country.

Second, and related to the first point, our results inform policy. Only $20 \%$ of the variation in export growth can be explained by variation in comparative advantage (Source x Product), leaving the lion's share to other forces that are outside the realm of national export promotion and industrial policies. Less than $20 \%$ of the variation in export growth can be explained by variation in bilateral forces (Source x Destination), and even these are not easily influenced by source country policies (arguably, multilateral trade resistance and destination tariff levels are not easily modified by source country policies). The high shares of product, destination, and product $\mathrm{x}$ destination effects further diminishes the emphasis on the nations where the exports originate.

Finally, the high share of idiosyncratic variance (Residual at the source-productdestination level of variation), importantly even for top 20 goods, points to even less ability to plan export successes through industrial policies. These results suggest it would be better to emphasize policies that can affect the ease of doing business more generally, and letting entrepreneurs in the source countries find markets for their products on their own (while also encouraging entrepreneurs in the destination countries to source products in the nations of origin). 


\section{Conclusions}

We contribute to the literature that documents the phenomenon of extreme export specialization and "granularity", where a few narrow product categories or export flows (here, at the 4-digit level) account for a surprisingly high share of total exports. Our most novel finding is that these specializations are not persistent over time. Using data from 1998 to 2010, we observe major reshufflings of the top ranks across products between 1998 and 2010 for all countries, including the entry of some products in 2010 that were nonexistent in 1998, and the disappearance of some goods that were in the top 20 in 1998. The instability holds also for export flows when including the destination component. Instability is somewhat lower for richer economies, and economies where exports are more diversified. Measurement error is unlikely to be an important determinant of this pattern.

In order to understand the instability of top exports we decompose the variance of growth from 1998 to 2010 of exports of product $p$ from source $s$ into variations due to (1) comparative advantage (source-by-product effects), (2) bilateral trade (source-bydestination effects), (3) global product growth (product effects), (4) overall destination demand growth (destination effects), (5) product-specific destination demand growth (destination-by-product effects), and (6) a residual. Our key finding is that changes in comparative advantage play a smaller role than we expected - only about 20 percent of the variance. We find that forces that do not involve the source country - see (3), (4) and (5) above - are as important as those that do - for example (1) and (2). The residual (6) accounts for about a third of the variance, stressing even more the instability and unpredictability of even the top export specializations. Richer economies' export growth is driven less by variation in comparative advantage and bilateral ties, as well as economies with more diversified export networks. This may reflect greater importance of intra-industry trade in more developed economies, which rely on trade networks for differentiated goods. 
Together these findings suggest that the common attribution of export successes and failures to the policies or other characteristics of the source country is exaggerated. The forces operating outside the source country (product trends, total destination demand, or product-specific destination) play a larger role than usually appreciated, and even bilateral relationships (source-by-destination effects), which account for 20 percent of overall variance, reflect policies and other characteristics in the destination importing country as much as in the source country. The shocks coming from outside the country help us understand the instability of top export specializations.

The combination of important forces in export specialization coming from outside the country and the remarkably high instability and unpredictability of top specializations imply that industrial policies that try to guide specialization will face grave challenges coping with fast-moving shocks. The findings could support policies that allow local entrepreneurs to rapidly enter and exit specializations by product and destination in response to rapidly changing opportunities in the global trade market. 


\section{REFERENCES}

Arezki, R., Hadri, K., Loungani, P. and Rao, Y. (2013): "Testing the Prebisch-Singer Hypothesis since 1650: Evidence from Panel Techniques that Allow for Multiple Breaks", International Monetary Fund WP/13/180.

Artopoulos, A., Friel, D. and Hallak, J. C. (2010), "Challenges of Exporting Differentiated Products to Developed Countries: The Case of SME-dominated Sectors in a Semi-Industrialized Country”, IDB working paper series No. IDB-WP-166.

Baldwin, R. (2005): "Heterogeneous Firms and Trade: Testable and Untestable Properties of the Melitz Model”, NBER Working Paper No. 11471.

Bernard, A. B., Jensen, J. B., Redding, S. J. and Schott, P. K. (2007): "Firms in International Trade", Journal of Economic Perspectives, Vol. 21, No. 3, Summer 2007, pp. 105-130.

Besedes, T. and Prusa, Thomas J. (2006a): "Ins, outs, and the duration of trade", Canadian Journal of Economics, Vol. 39, No. 1, February 2006, pp. 266-295.

Besedes, T. and Prusa, Thomas J. (2006b): "Product differentiation and duration of US import trade", Journal of International Economics, 70, pp. 339-358.

Cadot, O., Carrere, C. and Strauss-Kahn, V. (2011): "Export Diversification: What's Behind the Hump?", The Review of Economics and Statistics, May, 93(2), pp. 590-605.

Cadot, O., Disdier, A.-C., Jaud, M. and Suwa-Eisenmann (2014): "Big hits in exports: Growing by leaps and bounds", mimeo, Paris School of Economics. 
Cadot, O., Iacovone, L., Pierola, D. and Rauch, F. (2011): "Success and Failure of African Exporters", World Bank Policy Research Working Paper 5657.

di Giovanni, J. and Levchenko, A. A. (2012): "Country Size, International Trade, and Aggregate Fluctuations in Granular Economies", Journal of Political Economy, Vol. 120, No. 6 (December 2012), pp. 1083-1132.

di Giovanni, J., Levchenko, A. A. and Mejan, I. (2014): "Firms, Destinations, and Aggregate Fluctuations”, Econometrica, Vol. 82, No. 4 (July, 2014), pp. 1303-1340.

Easterly and Reshef, A. (2009): "Big Hits in Manufacturing Exports and Development", working paper, University of Virginia.

Easterly and Reshef, A. (2016): “African Export Successes: Surprises, Stylized Facts and Explanations", In David N. Weil, Sebastian Edwards and Simon Johnson (eds.), African Successes: Modernization and Development, 2016, NBER/University of Chicago Press.

Eaton, J., M. Eslava, M. Kugler, and J. Tybout (2007): "Export Dynamics in Colombia: Firm-Level Evidence”, NBER Working Paper No. 13531.

Eaton, J, and Kortum, S. (2002): “Technology, Geography, and Trade”, Econometrica, Vol. 70, No. 5 (September, 2002), pp. 1741-1779.

Eaton, J, Kortum, S. and Kramarz, F. (2011): “An Anatomy of International Trade: Evidence from French Firms", Econometrica, Vol. 79, No. 5 (September, 2011), pp. 1453-1498.

Fernandes, A. M., Freund, C., \& Pierola, M. D. (2016): “Exporter Behavior, Country Size and Stage of Development: Evidence from the Exporter Dynamics Database", Journal of Development Economics, 119, pp. 121-137. 
Frankel, J. A. and Romer, D. (1999): “Does Trade Cause Growth?”, The American Economic Review, Vol. 89, No. 3, pp. 379-399.

Freund, C. L. and Pierola, M. D. (2015): "Export Superstars", The Review of Economics and Statistics, Vol. 97, No. 5, pp. 1023-1032.

Gabaix, X. (2011), "The Granular Origins of Aggregate Fluctuations", Econometrica, Vol. 79, No. 3 (May, 2011), pp. 733-772.

Gabaix, X. (2016), "Power Laws in Economics: An Introduction", Journal of Economic Perspectives, Vol. 30(1), pp. 185-206.

Gaubert, C. and Itskhoki, O. (2016): "Granular Comparative Advantage”, working paper.

Hanson, G. H., Lind, N. and Muendler, M.-A. (2015): "The Dynamics of Comparative Advantage”, NBER Working Paper No. 21753

Harvey, D. I., Kellard, N. M., Madsen, J. B., and Wohar, M. E. (2010): "The PrebischSinger Hypothesis: Four Centuries of Evidence", The Review of Economics and Statistics, May 2010, Vol. 92, No. 2, pp. 367-377.

Hausmann, R. and Rodrik, D. (2006): "Doomed to Choose: Industrial Policy as Predicament", working paper, Harvard University, John F. Kennedy School of Government.

Hausmann, R., Hwang, J. and Rodrik, D. (2007): "What you export matters", Journal of Economic Growth, 12, pp. 1-25. 
Helpman, E., Melitz, M. and Rubinstein, Y. (2008): "Estimating Trade Flows: Trading Volumes and Trading Partners", The Quarterly Journal of Economics, 123(1), pp. 441487.

Helpman, E., Melitz, M. and Yeaple, S. (2008): "Export versus FDI with Heterogeneous Firms", The American Economic Review, Vol. 94, No. 1, pp. 300-316.

Imbs, J., and R. Wacziarg (2003): "Stages of Diversification", The American Economic Review, 93(1), pp. 63-86.

Levchenko, A. (2007): "Institutional Quality and International Trade", Review of Economic Studies, 74:3 (July 2007), pp. 791-819.

Levchenko, A. and Zhang, J. (2011): "The Evolution of Comparative Advantage: Measurement and Welfare Implications", NBER Working Paper No. 16806.

Moulton, B. R. (1990): “An Illustration of a Pitfall in Estimating the Effects of Aggregate Variables on Micro Units", The Review of Economics and Statistics, Vol. 72, No. 2, pp. 334-338.

Newman, M. E. J. (2005): "Power Laws, Pareto Distributions and Zipf's Law", Contemporary Physics, 46(5), pp. 323-351.

Nunn, Nathan (2007): "Relationship-Specificity, Incomplete Contracts, and the Pattern of Trade", The Quarterly Journal of Economics, Vol. 122, No. 2, pp. 569-600.

Panagariya, A. and Bagaria, P. (2013): "Some Surprising Facts about the Concentration of Trade across Commodities and Trading Partners", The World Economy, pp. 11651186. 


\section{APPENDIX}

\section{A. Definition of Commodities and Extractables}

We do our best to define the goods that belong to the broad categories of extractables and commodities, based on the analysis of the list of goods from http://www.foreigntrade.com/reference/hscode.htm and arrived to the following categories. We present here the list included in each category. Each entry is defined by the code and a small description available. Codes with four digits are already at the AG4 aggregation level, while those with just two digits are at the AG2 level and imply that all sub-goods are included.

\section{Commodities:}

09 coffee, tea, mate $\&$ spices

10 cereals

12 oil seeds/misc. grains/med. plants/straw

13 lac, gums, resins, etc.

1701 cane or beet sugar $\&$ chem pure sucrose, solid form

18 cocoa \& cocoa preparations except 1806 chocolate \& other food products containing cocoa

2401 tobacco, unmanufactured, tobacco refuse

4001 natural rubber, balata, gutta-percha, guayule, chicle and similar natural gums, in primary forms or in plates, sheets or strip

4501 natural cork, raw or simply prep, waste cork etc.

5001 silkworm cocoons suitable for reeling

5002 raw silk (not thrown)

5003 silk waste, including silk yarn waste etc.

5101 wool, not carded or combed

5102 fine or coarse animal hair, not carded or combed 
5103 waste of wool or of fine or coarse animal hair

5104 garnetted stock of wool/fine or coarse animal hair

5105 wool \& fine or coarse animal hair, carded \& combed

5201 cotton, not carded or combed

5202 cotton waste (including yarn waste etc.)

5203 cotton, carded or combed

5204 cotton sewing thread, retail packed or not

5301 flax, raw etc but not spun, flax tow and waste

5302 true hemp, raw etc not spun, true hemp tow and waste

5303 jute \& other text bast fibers nesoi, raw etc \& tow etc

5304 sisal \& other agave text fibers, raw etc \& tow etc

5305 coconut, abaca, ramie etc nesoi, raw etc, tow etc

Extractables:

25 salt, sulphur, earth \& stone, lime \& cement

26 ores slag \& ash

27 mineral fuels, oils, waxes \& bituminous sub

28 inorganic chem, org/inorg compounds of precious metals, isotopes

29 organic chemicals

7101 pearls, natural or cultured, not strung or set etc

7102 diamonds, worked or not, not mounted or set

7103 precious nesoi \& semiprec stones, not strung etc

7104 synth prec or semiprec stones etc, not strung etc

7105 dust \& powder of nat or synth prec or semipr stone

7106 silver (incl prec plated), unwr, semimfr or powder

7107 base metals clad w silver not frth wkd than smmnfetrd

7108 gold (incl put plated), unwr, semimfr or powder

7109 base metal or silver clad w gld not frtr wkd th smmnfetrd

7110 platinum, unwrought, semimfr forms or in powder fm

7111 base metal a slv a gld cld w put nt fr wkd th smnfetd

7112 waste $\&$ scrap of prec metal or metal clad w prec metal 
72 iron \& steel

7401 copper mattes, cement copper (precipitated copper)

7402 unrefined copper, copper anodes for electrolytic refining

7403 refined copper \& alloys (no mast alloy), unwrought

7404 copper waste and scrap

7405 master alloys of copper

7406 copper powders and flakes

7407 copper bars, rods and profiles

7408 copper wire

7409 copper plates, sheets \& strip, over $0.15 \mathrm{~mm}$ thick

7501 nickel mattes, nickel oxide sinters, other int prod

7502 nickel, unwrought

7503 nickel waste and scrap

7504 nickel powders and flakes

7505 nickel bars, rods, profiles and wire

7506 nickel plates, sheets, strip and foil

7601 aluminum, unwrought

7602 aluminum waste and scrap

7603 aluminum powders and flakes

7604 aluminum bars, rods and profiles

7605 aluminum wire

7606 aluminum plates, sheets \& strip over $2 \mathrm{~mm}$ thick

7607 aluminum foil (back or not) n/ov $2 \mathrm{~mm}$ th (ex back)

7801 lead, unwrought

7802 lead waste and scrap

7803 lead bars, rods, profiles and wire

7804 lead plates, sheets, strip, foil, powder \& flakes

7901 zinc, unwrought

7902 zinc waste and scrap

7903 zinc dust, powders and flakes 
7904 zinc bars, rods, profiles and wire

7905 zinc plates, sheet, strip and foil

8001 tin, unwrought

8002 tin waste and scrap

8003 tin bars, rods, profiles and wire

8004 tin plates, sheet and strip over $0.2 \mathrm{~mm}$ thick

8005 tin foil (backed or not), n/ov .2mm, tin pow \& flak

81 base metals nesoi, cermets, articles etc.

\section{B. Export Concentration Across Regions}

\begin{tabular}{|c|c|c|c|c|c|c|c|c|c|}
\hline \multirow[b]{3}{*}{ Rank } & \multicolumn{9}{|c|}{ Export Shares } \\
\hline & \multicolumn{3}{|c|}{ African Countries } & \multicolumn{3}{|c|}{ Non-African Countries } & \multicolumn{3}{|c|}{ OECD Countries } \\
\hline & All Goods & $\begin{array}{c}\text { Excl. } \\
\text { Extractables }\end{array}$ & $\begin{array}{r}\text { Excl. Extractables } \\
\text { and Commodities }\end{array}$ & $\begin{array}{c}\text { All } \\
\text { Goods }\end{array}$ & $\begin{array}{c}\text { Excl. } \\
\text { Extractables } \\
\end{array}$ & $\begin{array}{l}\text { Excl. Extractables } \\
\text { and Commodities }\end{array}$ & $\begin{array}{c}\text { All } \\
\text { Goods }\end{array}$ & $\begin{array}{c}\text { Excl. } \\
\text { Extractables }\end{array}$ & $\begin{array}{c}\text { Excl. } \\
\text { Extractables }\end{array}$ \\
\hline 1 & $37.3 \%$ & $30.9 \%$ & $21.7 \%$ & $25.2 \%$ & $20.9 \%$ & $21.4 \%$ & $12.7 \%$ & $11.5 \%$ & $11.7 \%$ \\
\hline 2 & $13.3 \%$ & $12.5 \%$ & $11.8 \%$ & $10.8 \%$ & $9.4 \%$ & $9.0 \%$ & $7.6 \%$ & $6.8 \%$ & $6.9 \%$ \\
\hline 3 & $8.3 \%$ & $8.0 \%$ & $7.5 \%$ & $6.5 \%$ & $6.0 \%$ & $6.1 \%$ & $4.5 \%$ & $5.0 \%$ & $5.1 \%$ \\
\hline 4 & $5.3 \%$ & $5.0 \%$ & $5.3 \%$ & $4.6 \%$ & $4.5 \%$ & $4.5 \%$ & $3.8 \%$ & $3.7 \%$ & $3.8 \%$ \\
\hline 5 & $3.6 \%$ & $3.6 \%$ & $4.3 \%$ & $3.5 \%$ & $3.5 \%$ & $3.5 \%$ & $3.0 \%$ & $3.1 \%$ & $3.1 \%$ \\
\hline 6 & $2.8 \%$ & $2.9 \%$ & $3.5 \%$ & $2.8 \%$ & $2.9 \%$ & $2.9 \%$ & $2.5 \%$ & $2.6 \%$ & $2.6 \%$ \\
\hline 7 & $2.2 \%$ & $2.3 \%$ & $2.9 \%$ & $2.3 \%$ & $2.5 \%$ & $2.5 \%$ & $2.1 \%$ & $2.2 \%$ & $2.3 \%$ \\
\hline 8 & $1.9 \%$ & $2.0 \%$ & $2.4 \%$ & $2.0 \%$ & $2.2 \%$ & $2.1 \%$ & $1.8 \%$ & $2.0 \%$ & $2.0 \%$ \\
\hline 9 & $1.5 \%$ & $1.8 \%$ & $2.2 \%$ & $1.7 \%$ & $1.9 \%$ & $1.8 \%$ & $1.6 \%$ & $1.7 \%$ & $1.7 \%$ \\
\hline 10 & $1.3 \%$ & $1.6 \%$ & $1.9 \%$ & $1.5 \%$ & $1.7 \%$ & $1.6 \%$ & $1.5 \%$ & $1.5 \%$ & $1.5 \%$ \\
\hline 11 & $1.2 \%$ & $1.4 \%$ & $1.7 \%$ & $1.3 \%$ & $1.5 \%$ & $1.5 \%$ & $1.3 \%$ & $1.4 \%$ & $1.4 \%$ \\
\hline 12 & $1.1 \%$ & $1.3 \%$ & $1.6 \%$ & $1.2 \%$ & $1.4 \%$ & $1.4 \%$ & $1.2 \%$ & $1.3 \%$ & $1.3 \%$ \\
\hline 13 & $0.9 \%$ & $1.2 \%$ & $1.4 \%$ & $1.1 \%$ & $1.3 \%$ & $1.3 \%$ & $1.1 \%$ & $1.2 \%$ & $1.2 \%$ \\
\hline 14 & $0.8 \%$ & $1.0 \%$ & $1.3 \%$ & $1.0 \%$ & $1.2 \%$ & $1.2 \%$ & $1.1 \%$ & $1.2 \%$ & $1.1 \%$ \\
\hline 15 & $0.7 \%$ & $0.9 \%$ & $1.2 \%$ & $0.9 \%$ & $1.1 \%$ & $1.1 \%$ & $1.0 \%$ & $1.1 \%$ & $1.1 \%$ \\
\hline 16 & $0.7 \%$ & $0.9 \%$ & $1.1 \%$ & $0.9 \%$ & $1.0 \%$ & $1.0 \%$ & $0.9 \%$ & $1.0 \%$ & $1.0 \%$ \\
\hline 17 & $0.6 \%$ & $0.8 \%$ & $1.1 \%$ & $0.8 \%$ & $0.9 \%$ & $1.0 \%$ & $0.9 \%$ & $1.0 \%$ & $1.0 \%$ \\
\hline 18 & $0.6 \%$ & $0.8 \%$ & $1.0 \%$ & $0.8 \%$ & $0.9 \%$ & $0.9 \%$ & $0.8 \%$ & $0.9 \%$ & $0.9 \%$ \\
\hline 19 & $0.5 \%$ & $0.7 \%$ & $0.9 \%$ & $0.7 \%$ & $0.8 \%$ & $0.9 \%$ & $0.8 \%$ & $0.9 \%$ & $0.9 \%$ \\
\hline 20 & $0.5 \%$ & $0.7 \%$ & $0.9 \%$ & $0.7 \%$ & $0.8 \%$ & $0.8 \%$ & $0.8 \%$ & $0.8 \%$ & $0.8 \%$ \\
\hline Total & $85.2 \%$ & $80.6 \%$ & $75.7 \%$ & $70.2 \%$ & $66.3 \%$ & $66.2 \%$ & $51.2 \%$ & $50.9 \%$ & $51.5 \%$ \\
\hline & & & & & & & & & \\
\hline \multicolumn{10}{|l|}{ Power } \\
\hline Law 20 & -0.66 & -0.75 & -0.86 & -0.82 & -0.94 & -0.94 & -1.08 & -1.14 & -1.13 \\
\hline
\end{tabular}

Note: Rankings are defined according to export value for the year 2010 .

Table A1: Export concentration among top 20 goods, distribution within top 20 goods, and power law coefficients. The table reports the average share of top 20 goods for all 
countries in groups (Africa, Non-African Countries, and OECD members) at the 4-digit HS code level. Source: COMTRADE. Data from 2010.

\begin{tabular}{|c|c|c|c|c|c|c|c|c|c|}
\hline \multirow[b]{3}{*}{ Rank } & \multicolumn{9}{|c|}{ Export Shares } \\
\hline & \multicolumn{3}{|c|}{ African Countries } & \multicolumn{3}{|c|}{ Non-African Countries } & \multicolumn{3}{|c|}{ OECD Countries } \\
\hline & $\begin{array}{c}\text { All } \\
\text { Goods }\end{array}$ & $\begin{array}{c}\text { Excl. } \\
\text { Extractables }\end{array}$ & $\begin{array}{l}\text { Excl. Extractables } \\
\text { and Commodities }\end{array}$ & $\begin{array}{c}\text { All } \\
\text { Goods }\end{array}$ & $\begin{array}{c}\text { Excl. } \\
\text { Extractables }\end{array}$ & $\begin{array}{l}\text { Excl. Extractables } \\
\text { and Commodities }\end{array}$ & $\begin{array}{c}\text { All } \\
\text { Goods }\end{array}$ & $\begin{array}{c}\text { Excl. } \\
\text { Extractables }\end{array}$ & $\begin{array}{l}\text { Excl. Extractables } \\
\text { and Commodities }\end{array}$ \\
\hline 1 & $20.8 \%$ & $14.5 \%$ & $14.7 \%$ & $14.5 \%$ & $12.4 \%$ & $13.1 \%$ & $5.5 \%$ & $4.5 \%$ & $4.6 \%$ \\
\hline 2 & $9.9 \%$ & $9.0 \%$ & $7.8 \%$ & $6.7 \%$ & $5.5 \%$ & $5.5 \%$ & $2.9 \%$ & $2.4 \%$ & $2.4 \%$ \\
\hline 3 & $7.1 \%$ & $6.5 \%$ & $5.1 \%$ & $4.6 \%$ & $3.8 \%$ & $3.8 \%$ & $2.2 \%$ & $1.8 \%$ & $1.8 \%$ \\
\hline 4 & $4.9 \%$ & $4.4 \%$ & $3.9 \%$ & $3.4 \%$ & $2.9 \%$ & $3.0 \%$ & $1.7 \%$ & $1.5 \%$ & $1.5 \%$ \\
\hline 5 & $3.9 \%$ & $3.6 \%$ & $3.2 \%$ & $2.7 \%$ & $2.4 \%$ & $2.4 \%$ & $1.4 \%$ & $1.4 \%$ & $1.4 \%$ \\
\hline 6 & $3.2 \%$ & $2.9 \%$ & $2.7 \%$ & $2.2 \%$ & $2.0 \%$ & $1.9 \%$ & $1.3 \%$ & $1.2 \%$ & $1.2 \%$ \\
\hline 7 & $2.4 \%$ & $2.5 \%$ & $2.2 \%$ & $1.9 \%$ & $1.8 \%$ & $1.7 \%$ & $1.2 \%$ & $1.1 \%$ & $1.1 \%$ \\
\hline 8 & $2.1 \%$ & $2.1 \%$ & $1.9 \%$ & $1.7 \%$ & $1.6 \%$ & $1.5 \%$ & $1.0 \%$ & $1.0 \%$ & $1.0 \%$ \\
\hline 9 & $1.8 \%$ & $1.8 \%$ & $1.7 \%$ & $1.5 \%$ & $1.4 \%$ & $1.3 \%$ & $0.9 \%$ & $0.9 \%$ & $0.9 \%$ \\
\hline 10 & $1.5 \%$ & $1.6 \%$ & $1.5 \%$ & $1.4 \%$ & $1.2 \%$ & $1.2 \%$ & $0.8 \%$ & $0.8 \%$ & $0.8 \%$ \\
\hline 11 & $1.4 \%$ & $1.4 \%$ & $1.4 \%$ & $1.2 \%$ & $1.1 \%$ & $1.1 \%$ & $0.8 \%$ & $0.8 \%$ & $0.8 \%$ \\
\hline 12 & $1.2 \%$ & $1.3 \%$ & $1.3 \%$ & $1.1 \%$ & $1.0 \%$ & $1.0 \%$ & $0.7 \%$ & $0.7 \%$ & $0.8 \%$ \\
\hline 13 & $1.1 \%$ & $1.2 \%$ & $1.2 \%$ & $1.0 \%$ & $1.0 \%$ & $1.0 \%$ & $0.7 \%$ & $0.7 \%$ & $0.7 \%$ \\
\hline 14 & $1.0 \%$ & $1.1 \%$ & $1.2 \%$ & $0.9 \%$ & $0.9 \%$ & $0.9 \%$ & $0.7 \%$ & $0.7 \%$ & $0.7 \%$ \\
\hline 15 & $1.0 \%$ & $1.1 \%$ & $1.1 \%$ & $0.8 \%$ & $0.8 \%$ & $0.8 \%$ & $0.6 \%$ & $0.6 \%$ & $0.7 \%$ \\
\hline 16 & $0.9 \%$ & $1.0 \%$ & $1.0 \%$ & $0.8 \%$ & $0.8 \%$ & $0.8 \%$ & $0.6 \%$ & $0.6 \%$ & $0.6 \%$ \\
\hline 17 & $0.8 \%$ & $0.9 \%$ & $1.0 \%$ & $0.7 \%$ & $0.8 \%$ & $0.7 \%$ & $0.6 \%$ & $0.6 \%$ & $0.6 \%$ \\
\hline 18 & $0.8 \%$ & $0.9 \%$ & $0.9 \%$ & $0.7 \%$ & $0.7 \%$ & $0.7 \%$ & $0.5 \%$ & $0.6 \%$ & $0.6 \%$ \\
\hline 19 & $0.7 \%$ & $0.8 \%$ & $0.9 \%$ & $0.6 \%$ & $0.7 \%$ & $0.7 \%$ & $0.5 \%$ & $0.5 \%$ & $0.5 \%$ \\
\hline 20 & $0.7 \%$ & $0.8 \%$ & $0.8 \%$ & $0.6 \%$ & $0.6 \%$ & $0.6 \%$ & $0.5 \%$ & $0.5 \%$ & $0.5 \%$ \\
\hline Total & $67.2 \%$ & $59.2 \%$ & $55.8 \%$ & $49.0 \%$ & $43.4 \%$ & $43.9 \%$ & $25.3 \%$ & $23.0 \%$ & $23.3 \%$ \\
\hline & & & & & & & & & \\
\hline \multicolumn{10}{|l|}{ Power } \\
\hline Law 20 & -0.85 & -0.96 & -1.04 & -0.95 & -1.04 & -1.02 & -1.28 & -1.45 & -1.45 \\
\hline
\end{tabular}

Table A2: Export concentration among top 20 export flows (product-by-destination), distribution within top 20 flows, and power law coefficients. The table reports the average share of top 20 goods for all countries in groups (Africa, Non-African Countries, and OECD members) at the 4-digit HS code level. Source: COMTRADE. Data from 2010. 
C. Export growth across regions and types of goods

\begin{tabular}{|l|r|r|r|r|r|}
\hline & Africa & America & Asia & Europe & Oceania \\
\hline Avg. Country & 285 & 261 & 423 & 249 & 142 \\
\hline Avg. Country, Top 5 in $\mathbf{1 9 9 8}$ & 390 & 190 & 293 & 157 & 142 \\
\hline Avg. Country, with share $\mathbf{>} \mathbf{1 0 \%}$ in $\mathbf{1 9 9 8}$ & 444 & 155 & 320 & 142 & 235 \\
\hline Median Country & 214 & 195 & 279 & 193 & 122 \\
\hline Perc. 90th Country & 521 & 464 & 642 & 419 & 279 \\
\hline Perc. 10th Country & 98 & 91 & 106 & 138 & 45 \\
\hline Avg. Country, w/o Extractable & 331 & 195 & 285 & 230 & 111 \\
\hline Avg. Country w/o Ext. or Commodity & 409 & 218 & $\mathbf{2 9 3}$ & 229 & 134 \\
\hline Avg. w/o Extractable, Top 5 in 1998 & 235 & 164 & $\mathbf{2 8 7}$ & 150 & 111 \\
\hline Avg. w/o Ext. or Commodity, Top 5 in 1998 & 244 & 159 & 290 & 150 & 134 \\
\hline
\end{tabular}

Table A3: Export growth across regions and types of goods. Details: “Avg. Country” is the average country level export growth $(1998=100)$ in each region; "Top 5 in 1998" refers to the 5 biggest countries in each region in 1998; "with share $>10 \%$ in 1998" refers to the countries which exported more than $10 \%$ of total exported in each region in 1998; Median, Perc. $90^{\text {th }}$ and Perc. $10^{\text {th }}$ refer to the corresponding country quantile in each region regarding export growth; "w/o extractable" and "w/o ext. or commodity" removes the corresponding set of goods from the exports calculations.

\section{Top Exports Churning: Additional Figures}

In Uganda, electrical energy went from being \#5 in 1998 to \#28 in 2010, while cement went from \#14 to \#4. Cement in 1998 had almost all gone to Democratic Republic of Congo, but Uganda had added an even larger market in Rwanda in 2010 (possibly reflecting Rwanda's rapid growth from 1998 to 2010). Cell phones also show a big increase in rank as an export; these are likely to be re-exports, since imports of cell phones are even larger and it is unlikely that Uganda is manufacturing cell phones as a final good. 
In Japan, computers went from the \#3 export in 1998 to \#67 in 2010, while printing machinery went from \#50 in 1998 to \#7 in 2010. Japan's \#5 export in 2010 was "Machines used to produce semiconductors, integrated circuits, and flat panels", while this category was virtually nonexistent in 1998. In the richer countries at the technological frontier, technology changes are an added source of export instability. 


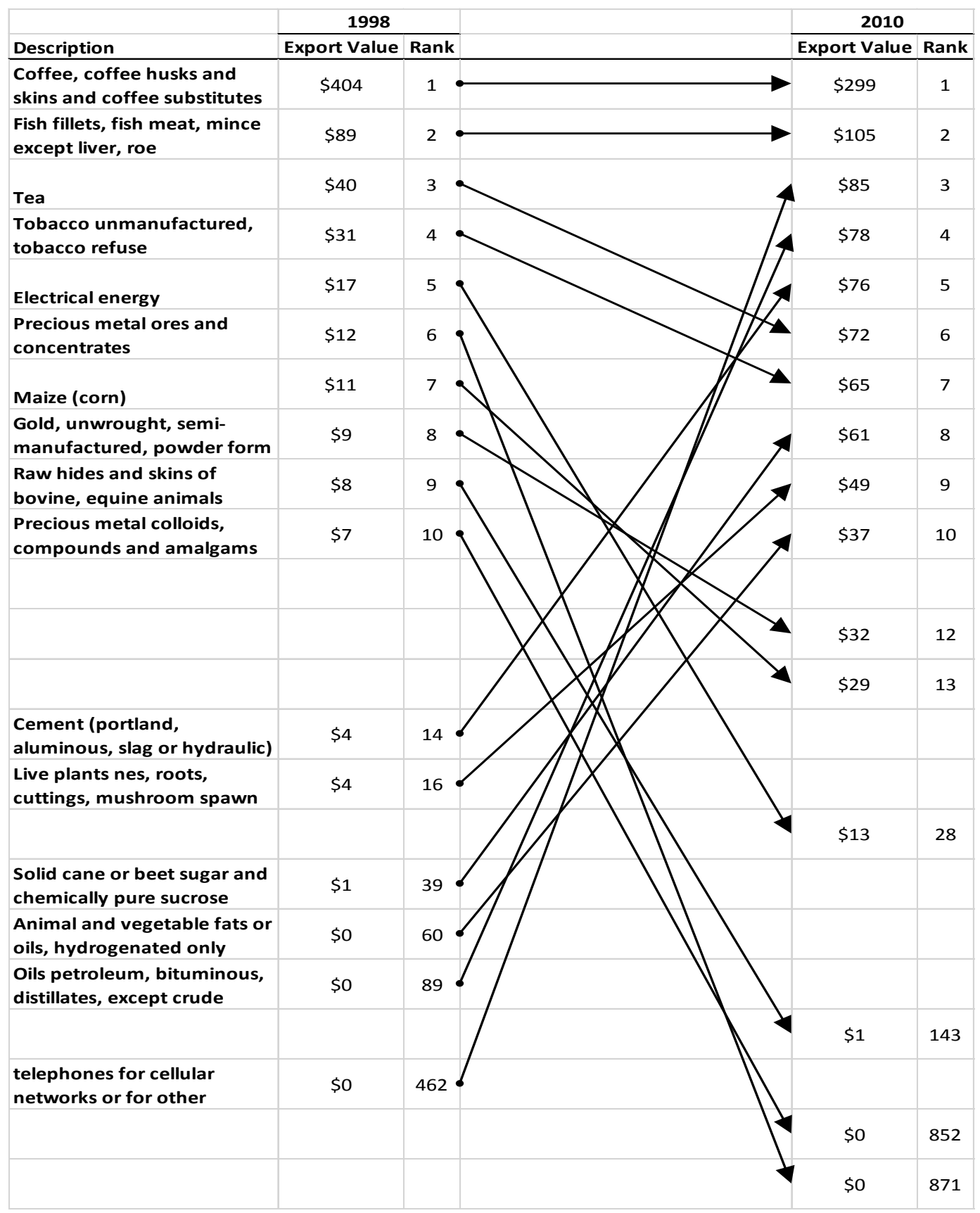

Figure A1-A: Top exports churning in Uganda. The figure reports the ranks and values of top ten exports in 1998 and in 2010, and their ranking and value in the opposite end of the sample, all in 2012 prices (thousands of U.S. dollars). Source: COMTRADE. 


\begin{tabular}{|c|c|c|c|c|}
\hline \multirow[b]{2}{*}{ Description } & \multicolumn{2}{|l|}{1998} & \multicolumn{2}{|l|}{2010} \\
\hline & Export Value & Rank & Export Value & Rank \\
\hline $\begin{array}{l}\text { Motor vehicles for transport } \\
\text { of persons (except buses) }\end{array}$ & $\$ 71,598$ & 1 & $\$ 95,146$ & 1 \\
\hline $\begin{array}{l}\text { Electronic integrated circuits } \\
\text { and microassemblies }\end{array}$ & $\$ 27,284$ & 2 & $\$ 36,944$ & 2 \\
\hline $\begin{array}{l}\text { Automatic data processing } \\
\text { machines (computers) }\end{array}$ & $\$ 22,079$ & 3 & $\$ 36,356$ & 3 \\
\hline $\begin{array}{l}\text { Parts and accessories for } \\
\text { motor vehicles }\end{array}$ & $\$ 17,517$ & 4 & $\$ 26,944$ & 4 \\
\hline $\begin{array}{l}\text { Parts, accessories, except } \\
\text { covers, for office machines }\end{array}$ & $\$ 16,664$ & 5 & $\$ 20,091$ & 5 \\
\hline $\begin{array}{l}\text { Passenger and goods } \\
\text { transport ships, boats }\end{array}$ & $\$ 13,847$ & 6 & $\$ 16,007$ & 6 \\
\hline $\begin{array}{l}\text { Motor vehicles for the } \\
\text { transport of goods }\end{array}$ & $\$ 10,407$ & 7 & $\$ 13,102$ & 7 \\
\hline $\begin{array}{l}\text { Radio and TV transmitters, } \\
\text { television cameras }\end{array}$ & $\$ 8,407$ & 8 & $\$ 12,271$ & 8 \\
\hline $\begin{array}{l}\text { Machines nes having } \\
\text { individual functions }\end{array}$ & $\$ 8,278$ & 9 & $\$ 10,822$ & 9 \\
\hline Photo-copying apparatus & $\$ 7,804$ & 10 & $\$ 9,810$ & 10 \\
\hline \multirow[t]{2}{*}{$\begin{array}{l}\text { Diodes, transistors, semi- } \\
\text { conductors, etc }\end{array}$} & $\$ 7,122$ & 11 & & \\
\hline & & & $\$ 9,523$ & 12 \\
\hline \multirow[t]{3}{*}{$\begin{array}{l}\text { Printing and ancillary } \\
\text { machinery }\end{array}$} & $\$ 2,063$ & 49 & & \\
\hline & & & $\$ 2,817$ & 64 \\
\hline & & & $\$ 2,786$ & 66 \\
\hline \multirow[t]{2}{*}{$\begin{array}{l}\text { Oils petroleum, bituminous, } \\
\text { distillates, except crude }\end{array}$} & $\$ 1,123$ & 96 & & \\
\hline & & & $\$ 0$ & 1174 \\
\hline $\begin{array}{l}\text { kind used solely or principally } \\
\text { for the manufacture of }\end{array}$ & $\$ 0$ & $1188^{d}$ & & \\
\hline
\end{tabular}

Figure A1-B: Top exports churning in Japan. The figure reports the ranks and values of top ten exports in 1998 and in 2010, and their ranking and value in the opposite end of the sample, all in 2012 prices (thousands of U.S. dollars). Source: COMTRADE. 


\section{E. Descriptive Statistics}

A. Descriptive Statistics

\begin{tabular}{|c|c|c|c|c|c|c|c|}
\hline & Mean & Std. Dev. & $\begin{array}{c}\text { 25th } \\
\text { Percentile }\end{array}$ & Median & \begin{tabular}{|c|} 
75th \\
Percentile \\
\end{tabular} & Min & Max \\
\hline In(Initial GDP per capita) & 8.91 & 1.24 & 7.96 & 9.04 & 9.97 & 6.43 & 10.82 \\
\hline Initial Destination Concentration Index & 0.35 & 0.17 & 0.23 & 0.31 & 0.41 & 0.1 & 0.88 \\
\hline In(Initial GDP Total) & 24.65 & 2.06 & 22.96 & 24.53 & 26.05 & 20.89 & 30.18 \\
\hline In(Initial Population) & 16.31 & 1.57 & 15.32 & 16.12 & 17.24 & 12.49 & 20.94 \\
\hline $\ln ($ Land Size) & 12.12 & 2.05 & 11.14 & 12.22 & 13.27 & 5.77 & 16.05 \\
\hline Initial Credit/GDP & 46.96 & 47.83 & 11.31 & 30.76 & 64.38 & 2.79 & 222.51 \\
\hline Initial Herfindahl Index over Destinations & 0.51 & 0.32 & 0.23 & 0.44 & 0.83 & 0.03 & 1 \\
\hline
\end{tabular}

B. Pairwise Correlations

\begin{tabular}{|l|c|c|c|c|c|c|}
\hline & $\begin{array}{c}\text { In(Initial GDP } \\
\text { per capita) }\end{array}$ & $\begin{array}{c}\text { Destination } \\
\text { Concentration }\end{array}$ & $\begin{array}{c}\text { In(Initial GDP) } \\
\text { Population) }\end{array}$ & $\begin{array}{c}\text { In (Landial } \\
\text { Credit/GDP }\end{array}$ \\
\hline In(Initial GDP per capita) & 1 & & & & & \\
\hline Initial Destination Concentration Index & -0.34 & 1 & & & & \\
\hline $\operatorname{In}($ Initial GDP Total) & 0.64 & -0.47 & 1 & & & \\
\hline In(Initial Population) & -0.17 & -0.27 & 0.64 & 1 & & \\
\hline $\operatorname{In}($ Land Size) & -0.23 & -0.01 & 0.43 & 0.74 & 1 & \\
\hline Initial Credit/GDP & 0.60 & -0.34 & 0.55 & 0.10 & -0.12 & 1 \\
\hline
\end{tabular}

Table A4: Descriptive statistics and pairwise correlations for regressions in Table 5. All statistics based on the sample in Table 5, a maximum of 103 cross country observations, depending on data availability, except for Initial Herfindahl Index over Destinations, which is a sample of 90,317 country-by-product observations. Initial Herfindahl Index over Destinations is calculated for each product and each source exporting country. Destination Concentration Index is the weighted average of the Initial Herfindahl Index over Destinations within a source exporting country, where the weights are export values. Source for export is COMTRADE. Source for GDP, population, land mass and credit (M3) are from the World Bank's World Development Indicators. All variables pertain to 1998 (hence, “initial”). 


\section{F. True Growth and Bounded Growth}

Bounded growth is a monotonic transformation of true growth, that has a range of $[-2,2]$; -2 represents disappearing goods that were exported in 1998 but not in 2010, and 2 represents new goods that were not exported in 1998 but are in 2010:

$$
x_{s d p}=\frac{x_{s d p, 2010}-x_{s d p, 1998}}{\frac{1}{2}\left(x_{s d p, 2010}+x_{s d p, 1998}\right)},
$$

where $x_{s d p, t}$ is the value in year $t$ of (in our case) exports from source $s$ to destination $d$ of product $p$, and $x_{s d p}$ is the value of bounded growth. Thus, bounded growth has the virtue of explicitly taking into account new goods that emerge, as well as old goods that disappear. That is, we take into account $x_{s d p, t}$ export values that are zero. While bounded growth is always strictly below true growth except at zero, it is a good approximation for true growth that is not extreme. For example, when true growth is between $-40 \%$ and $50 \%$, bounded growth is less than 10 percent points below it. Bounded growth deviates from true growth the most for new ( $\infty$ is represented by 2 ) and disappearing goods ( -1 is represented by -2). The following figures illustrate these features. 


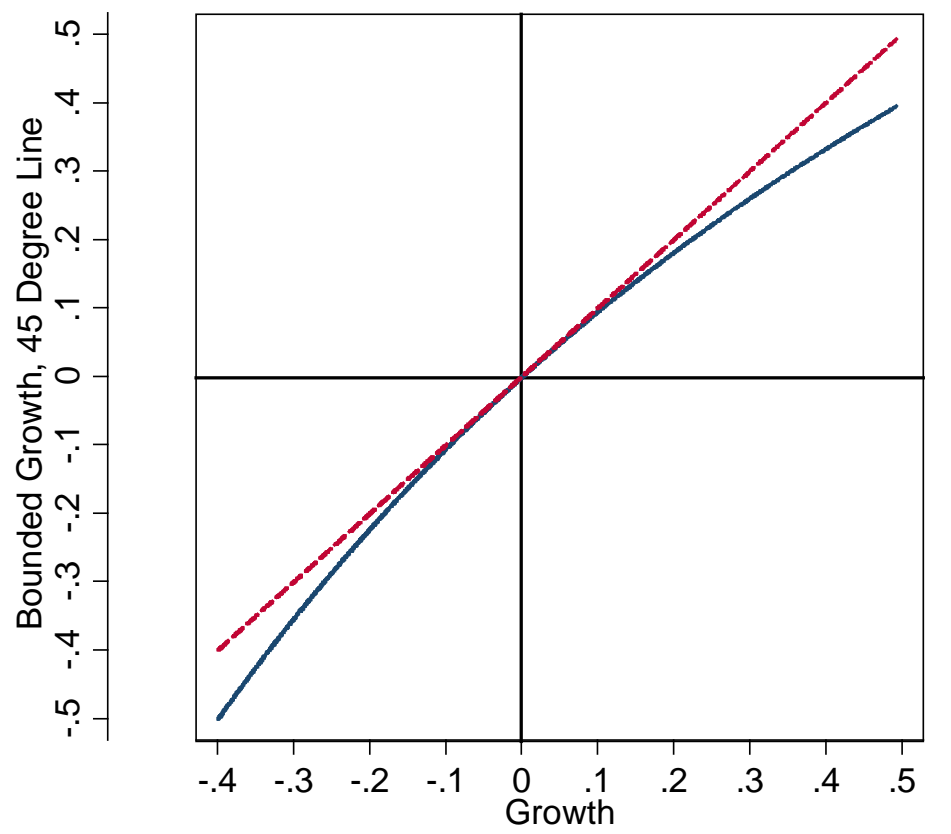

Bounded Growth ------- 45 Degree Line

Figure A2-A: Restricting the difference between true growth and bounded growth to 0.1 in absolute value gives a range of [-0.4,0.5] for true growth. 


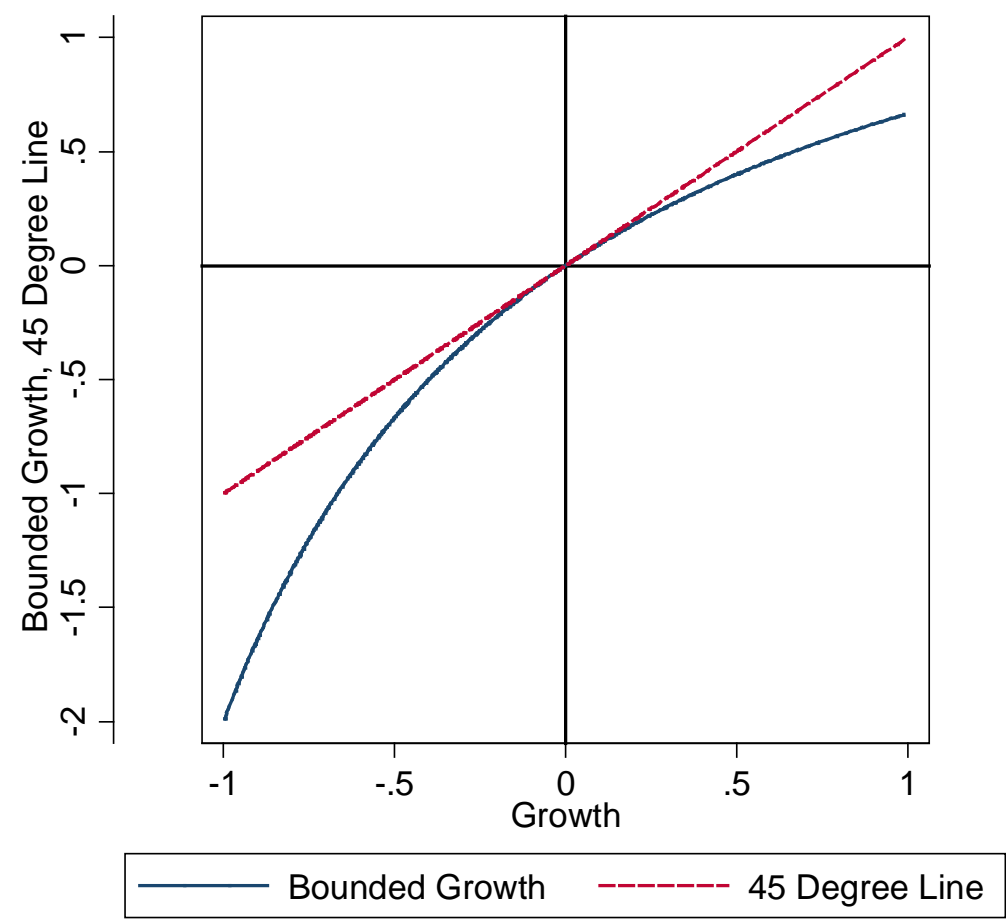

Figure A2-B: True growth and bounded growth, when true growth is in $[-1,1]$.

\section{G. Fixed Effect Estimation}

Our estimation specification is

$$
x_{s d p}=\alpha+\theta_{s}+\vartheta_{s g}+\beta_{s d}+\gamma_{g}+\delta_{d}+\rho_{d g}+\varepsilon_{s d g}
$$

where all variables are in changes, e.g., $\alpha=\alpha_{2010}-\alpha_{1998}: \alpha$ captures changes in global aggregate demand; $\theta_{s}$ captures changes in aggregate productivity (absolute advantage) in country $s ; \vartheta_{s g}$ captures changes in the comparative advantage of country $s$ in product $p ; \beta_{s d}$ captures changes in bilateral factors (bilateral resistance) that affect 
exporting from source country $s$ to destination country $d ; \gamma_{p}$ changes in global aggregate demand for product $p ; \delta_{d}$ captures changes in aggregate demand in destination country $d$; $\rho_{d p}$ captures changes in relative demand in destination $d$ for product $p$; and $\varepsilon_{s d p}$ is the residual, which may reflect changes in source-destination-product specific demand or supply shocks.

Estimating this using all countries directly is not computationally feasible due to the large number of dummy variables present. The purpose of this section is to show how these estimates can be recovered from a country-by-country estimation.

Fixing a country $s$, we can estimate a simple regression with product and destination fixed effects

$$
x_{d p}^{s}=\pi^{s}+\pi_{g}^{s}+\pi_{d}^{s}+\pi_{d g}^{s},
$$

where $\pi^{S}$ is a source country s-specific intercept, $\pi_{g}^{S}$ is source country s-specific product $g$ fixed effect, $\pi_{d}^{s}$ source country s-specific destination $d$ fixed effect and $\pi_{d g}^{s}$ is source country s-specific residual.

Comparing with the above we see that $\pi^{s}=\alpha+\theta_{s} ; \pi_{g}^{S}=\gamma_{g}+\vartheta_{s g} ; \pi_{d}^{S}=\delta_{d}+$ $\beta_{s d}$ and $\pi_{d g}^{s}=\rho_{d g}+\varepsilon_{s d g}$. Therefore, we can recover our parameters of interest by taking the appropriate averages. We first collect all our country-by-country estimates by assigning the ones corresponding to each trade flow. Note that this repeats some of the fixed effects. For example, consider exports of good $g$ from country $s$ to destinations $d 1$ and $d 2$. These two flows constitute two vectors of fixed effects: $\left[\pi^{s}, \pi_{g}^{s}, \pi_{d 1}^{s}, \pi_{d 1 g}^{s}\right]$ and $\left[\pi^{S}, \pi_{g}^{S}, \pi_{d 2}^{S}, \pi_{d 2 g}^{S}\right]$. Hence, in this example, $\pi^{S}$ and $\pi_{g}^{S}$ are repeated. In general, $\pi^{S}$ will be repeated for each flow from country s. Similarly, $\pi_{g}^{s}$ will be repeated for each flow of good $g$ from country $s$, and $\pi_{d}^{s}$ will be repeated for each flow from country $s$ to 
destination $d$. In order to allow weighting we add the average value of the s-d-g flow in 1998 and 2010 to the vector of estimates, i.e. $\left[\frac{x_{d p, 1998}^{s}+x_{d p, 2010}^{s}}{2}, \pi^{s}, \pi_{g}^{S}, \pi_{d 2}^{S}, \pi_{d 2 g}^{S}\right]$.

Now we can extract the estimates of interest by taking the appropriate averages (weighing if desired). For example, without using weights, to identify $\alpha$ we take the average of $\hat{\pi}^{s}$

$$
\hat{\alpha}=\frac{1}{N_{f}} \sum_{f=1}^{N_{f}} \hat{\pi}^{S(f)}
$$

where $S(f)$ returns the country of flow $f$ and $N_{f}$ is the total number of flows. Then, the following deviations identify $\theta_{s}$ :

$$
\hat{\theta}_{s}=\hat{\pi}^{s}-\hat{\alpha}
$$

In order to retrieve $\delta_{d}$ we take the average of $\hat{\pi}_{d}^{s}$ over flows with destination $d$

$$
\hat{\delta}_{d}=\frac{1}{\sum_{f=1}^{N_{f}} 1\{D(f)=d\}} \sum_{f=1}^{N_{f}} \hat{\pi}_{D(f)}^{S(f)} 1\{D(f)=d\},
$$

where $D(f)$ returns the destination of flow $f$ and $1\{D(f)=d\}$ is the identity function that returns one if the destination of flow $f$ is $d$. Then, $\beta_{s d}$ is identified by the appropriate deviation

$$
\hat{\beta}_{s d}=\hat{\pi}_{d}^{s}-\hat{\delta}_{d}
$$

Similar analysis can be done to obtain the rest of the estimates of interest. 


\section{H. Appendix Tables for Fixed Effect Estimation}

\begin{tabular}{|c|c|c|c|c|c|c|c|c|}
\hline & \multirow[b]{2}{*}{ World } & \multirow[b]{2}{*}{ Africa } & \multirow[b]{2}{*}{ America } & \multirow[b]{2}{*}{ Asia } & \multirow[b]{2}{*}{ Europe } & \multicolumn{3}{|c|}{ Export Growth } \\
\hline & & & & & & Low & Medium & High \\
\hline Standard deviation & 1.62 & 1.77 & 1.62 & 1.59 & 1.54 & 1.66 & 1.60 & 1.63 \\
\hline \multicolumn{9}{|l|}{ A. Perecent of overall variance: Variances } \\
\hline Source $x$ Product & 19 & 24 & 20 & 18 & 15 & 17 & 17 & 23 \\
\hline Source $x$ Destination & 18 & 25 & 16 & 18 & 14 & 18 & 17 & 21 \\
\hline Product & 12 & 15 & 12 & 10 & 10 & 11 & 11 & 14 \\
\hline Destination & 11 & 13 & 9 & 11 & 11 & 11 & 11 & 11 \\
\hline Destination $x$ Product & 19 & 17 & 20 & 19 & 18 & 16 & 20 & 19 \\
\hline Residual & 34 & 26 & 34 & 33 & 41 & 36 & 36 & 31 \\
\hline \multicolumn{9}{|l|}{ B. Perecent of overall variance: Covariances } \\
\hline $2 \times \operatorname{Cov}($ Source $\times$ Product, Source $\times$ Destination) & 0 & 0 & 1 & 0 & 0 & 1 & 0 & 0 \\
\hline $2 \times \operatorname{Cov}$ (Product, Source $\times$ Product) & -12 & -21 & -14 & -7 & -9 & -11 & -11 & -17 \\
\hline $2 \times \operatorname{Cov}$ (Product, Source $\times$ Destination) & 0 & 0 & 0 & 0 & 0 & 0 & 0 & 0 \\
\hline $2 \times \operatorname{Cov}($ Destination, Source $\times$ Product) & 1 & 2 & 1 & 1 & 0 & 1 & 1 & 1 \\
\hline $2 \times \operatorname{Cov}($ Destination , Source $\times$ Destination) & -3 & -4 & -2 & -5 & -2 & -1 & -3 & -6 \\
\hline $2 \times \operatorname{Cov}($ Destination, Product) & 0 & 1 & 0 & 0 & 0 & 0 & 0 & 0 \\
\hline $2 \times \operatorname{Cov}$ (Destination $\times$ Product, Source $\times$ Product) & 0 & 0 & 0 & 0 & 0 & 0 & 0 & 0 \\
\hline $2 \times \operatorname{Cov}$ (Destination $x$ Product, Source $x$ Destination) & 1 & 1 & 1 & 1 & 1 & 1 & 1 & 1 \\
\hline $2 \times \operatorname{Cov}($ Destination $\times$ Product , Product) & 0 & 0 & 0 & 0 & 0 & 0 & 0 & 0 \\
\hline $2 \times \operatorname{Cov}($ Destination $\times$ Product, Destination) & 0 & 0 & 0 & 0 & 0 & 0 & 0 & 0 \\
\hline Total & 100 & 100 & 100 & 100 & 100 & 100 & 100 & 100 \\
\hline
\end{tabular}

Table A5. Variance decompositions of export growth of top 20 export flows in 1998-2010

for the average country within each subset of countries. Countries are classified as "low" export growth if their export growth is at or below the 25th percentile, "medium" if between 25th and 75th percentiles, and "high" if export growth is at or above the 75th percentile of export distribution. Data: COMTRADE. 


\begin{tabular}{|c|c|c|c|c|c|c|c|c|}
\hline & \multirow[b]{2}{*}{ World } & \multirow[b]{2}{*}{ Africa } & \multirow[b]{2}{*}{ America } & \multirow[b]{2}{*}{ Asia } & \multirow[b]{2}{*}{ Europe } & \multicolumn{3}{|c|}{ Export Growth } \\
\hline & & & & & & Low & Medium & High \\
\hline Standard deviation & 1.67 & 1.77 & 1.66 & 1.63 & 1.63 & 1.71 & 1.66 & 1.64 \\
\hline \multicolumn{9}{|l|}{ A. Perecent of overall variance: Variances } \\
\hline Source $x$ Product & 18 & 23 & 21 & 17 & 14 & 17 & 17 & 20 \\
\hline Source $x$ Destination & 11 & 15 & 9 & 14 & 7 & 10 & 8 & 16 \\
\hline Product & 4 & 3 & 4 & 4 & 4 & 4 & 4 & 4 \\
\hline Destination & 11 & 15 & 9 & 10 & 10 & 12 & 10 & 12 \\
\hline Destination $\mathrm{x}$ Product & 6 & 6 & 6 & 6 & 6 & 6 & 6 & 7 \\
\hline Residual & 50 & 39 & 50 & 51 & 57 & 50 & 53 & 45 \\
\hline \multicolumn{9}{|l|}{ B. Perecent of overall variance: Covariances } \\
\hline $2 \times \operatorname{Cov}($ Source $\times$ Product, Source $\times$ Destination) & 1 & 2 & 0 & 1 & 1 & 1 & 1 & 1 \\
\hline $2 \times \operatorname{Cov}$ (Product, Source $\times$ Product) & -1 & -2 & -2 & -1 & 0 & -1 & -1 & -2 \\
\hline $2 \times \operatorname{Cov}$ (Product, Source $\times$ Destination) & 0 & 0 & 0 & 0 & 0 & 0 & 0 & 1 \\
\hline $2 \times \operatorname{Cov}($ Destination, Source $\times$ Product) & 1 & 2 & 0 & 1 & 1 & 1 & 1 & 1 \\
\hline $2 \times \operatorname{Cov}$ (Destination, Source $\times$ Destination) & -2 & -4 & 0 & -5 & 0 & -1 & -1 & -5 \\
\hline $2 \times \operatorname{Cov}$ (Destination, Product) & 0 & 0 & 0 & 0 & 0 & 0 & 0 & 0 \\
\hline $2 \times \operatorname{Cov}($ Destination $\times$ Product, Source $\times$ Product) & 0 & 1 & 0 & 0 & 0 & 0 & 0 & 0 \\
\hline $2 \times \operatorname{Cov}($ Destination $\times$ Product, Source $\times$ Destination) & 0 & 0 & 0 & 0 & 0 & 0 & 0 & 0 \\
\hline $2 \times \operatorname{Cov}($ Destination $\times$ Product, Product) & 0 & 0 & 0 & 0 & 0 & 0 & 0 & 0 \\
\hline $2 \times \operatorname{Cov}$ (Destination $\times$ Product, Destination) & 0 & 0 & 0 & 0 & 0 & 0 & 0 & 0 \\
\hline Total & 100 & 100 & 100 & 100 & 100 & 100 & 100 & 100 \\
\hline
\end{tabular}

Table A6. Variance decompositions of export growth of all export flows in 1998-2010 for the average country within each subset of countries. Countries are classified as "low" export growth if their export growth is below the 25th percentile, "medium" if between 25th and 75th percentiles, and "high" if export growth is above the 75th percentile of export distribution. Data: COMTRADE. 


\begin{tabular}{|c|c|c|c|c|c|c|c|c|}
\hline & \multirow[b]{2}{*}{ World } & \multirow[b]{2}{*}{ Africa } & \multirow[b]{2}{*}{ America } & \multirow[b]{2}{*}{ Asia } & \multirow[b]{2}{*}{ Europe } & \multicolumn{3}{|c|}{ Export Growth } \\
\hline & & & & & & Low & Medium & High \\
\hline Standard deviation & 1.30 & 1.18 & 1.18 & 1.18 & 1.18 & 1.31 & 1.29 & 1.32 \\
\hline \multicolumn{9}{|l|}{ A. Perecent of overall variance: Variances } \\
\hline Source $x$ Product & 31 & 47 & 33 & 30 & 20 & 33 & 27 & 36 \\
\hline Source $x$ Destination & 21 & 34 & 18 & 17 & 18 & 21 & 20 & 24 \\
\hline Product & 19 & 27 & 17 & 22 & 14 & 18 & 20 & 19 \\
\hline Destination & 3 & 2 & 2 & 3 & 3 & 3 & 3 & 3 \\
\hline Destination $\mathrm{x}$ Product & 22 & 19 & 24 & 23 & 22 & 20 & 24 & 21 \\
\hline Residual & 33 & 23 & 31 & 32 & 40 & 34 & 34 & 28 \\
\hline \multicolumn{9}{|l|}{ B. Perecent of overall variance: Covariances } \\
\hline $2 \times \operatorname{Cov}($ Source $x$ Product , Source $x$ Destination) & -5 & -14 & -2 & -2 & -3 & -7 & -3 & -5 \\
\hline $2 \times \operatorname{Cov}$ (Product, Source $\times$ Product) & -23 & -37 & -23 & -24 & -13 & -23 & -23 & -21 \\
\hline $2 \times \operatorname{Cov}$ (Product, Source $\times$ Destination) & -1 & -1 & -1 & -1 & -1 & 0 & -1 & -2 \\
\hline $2 \times \operatorname{Cov}$ (Destination, Source $\times$ Product) & 0 & 0 & -1 & 0 & 0 & 0 & 0 & -1 \\
\hline $2 \times \operatorname{Cov}$ (Destination, Source $x$ Destination) & -1 & -2 & -1 & -1 & -1 & 0 & -1 & -2 \\
\hline $2 \times \operatorname{Cov}$ (Destination, Product) & 0 & 0 & 0 & 0 & 0 & 0 & 0 & 0 \\
\hline $2 \times \operatorname{Cov}($ Destination $\times$ Product , Source $\times$ Product) & 0 & 1 & 0 & 0 & 0 & 1 & 0 & 0 \\
\hline $2 \times \operatorname{Cov}$ (Destination $\times$ Product, Source $\times$ Destination) & 1 & 0 & 1 & 1 & 0 & 1 & 1 & 0 \\
\hline $2 \times \operatorname{Cov}$ (Destination $\times$ Product, Product) & 0 & 0 & 0 & 0 & 0 & 0 & 0 & 0 \\
\hline $2 \times \operatorname{Cov}($ Destination $\times$ Product, Destination) & 0 & 0 & 0 & 0 & 0 & 0 & 0 & 0 \\
\hline Total & 100 & 100 & 100 & 100 & 100 & 100 & 100 & 100 \\
\hline
\end{tabular}

Table A7. Variance decompositions of export growth of top 20 NON-ZERO export flows in 1998-2010 for the average country within each subset of countries. The sample is restricted to export flows that are strictly positive in both 1998 and 2010. Countries are classified as "low" export growth if their export growth is at or below the 25th percentile, "medium" if between 25th and 75th percentiles, and "high" if export growth is at or above the 75th percentile of export distribution. Data: COMTRADE. 


\begin{tabular}{|c|c|c|c|c|c|c|c|c|}
\hline & \multirow[b]{2}{*}{ World } & \multirow[b]{2}{*}{ Africa } & \multirow[b]{2}{*}{ America } & \multirow[b]{2}{*}{ Asia } & \multirow[b]{2}{*}{ Europe } & \multicolumn{3}{|c|}{ Export Growth } \\
\hline & & & & & & Low & Medium & High \\
\hline Standard deviation & 1.67 & 1.77 & 1.66 & 1.63 & 1.63 & 1.71 & 1.66 & 1.64 \\
\hline \multicolumn{9}{|l|}{ A. Perecent of overall variance: Variances } \\
\hline Source $x$ Product & 18 & 23 & 21 & 17 & 14 & 17 & 17 & 20 \\
\hline Source $x$ Destination & 11 & 15 & 9 & 14 & 7 & 10 & 8 & 16 \\
\hline Product & 4 & 3 & 4 & 4 & 4 & 4 & 4 & 4 \\
\hline Destination & 11 & 15 & 9 & 10 & 10 & 12 & 10 & 12 \\
\hline Destination $\times$ Product & 6 & 6 & 6 & 6 & 6 & 6 & 6 & 7 \\
\hline Residual & 50 & 39 & 50 & 51 & 57 & 50 & 53 & 45 \\
\hline \multirow{2}{*}{\multicolumn{9}{|c|}{ B. Perecent of overall variance: Covariances }} \\
\hline & & & & & & & & \\
\hline $2 \times \operatorname{Cov}($ Source $x$ Product, Source $x$ Destination) & 1 & 2 & 0 & 1 & 1 & 1 & 1 & 1 \\
\hline $2 \times \operatorname{Cov}$ (Product, Source $\times$ Product) & -1 & -2 & -2 & -1 & 0 & -1 & -1 & -2 \\
\hline $2 \times \operatorname{Cov}($ Product, Source $\times$ Destination) & 0 & 0 & 0 & 0 & 0 & 0 & 0 & 1 \\
\hline $2 \times \operatorname{Cov}($ Destination, Source $\times$ Product) & 1 & 2 & 0 & 1 & 1 & 1 & 1 & 1 \\
\hline $2 \times \operatorname{Cov}($ Destination , Source $\times$ Destination) & -2 & -4 & 0 & -5 & 0 & -1 & -1 & -5 \\
\hline $2 \times \operatorname{Cov}$ (Destination, Product) & 0 & 0 & 0 & 0 & 0 & 0 & 0 & 0 \\
\hline $2 \times \operatorname{Cov}$ (Destination $\times$ Product, Source $\times$ Product) & 0 & 1 & 0 & 0 & 0 & 0 & 0 & 0 \\
\hline $2 \times \operatorname{Cov}$ (Destination $\times$ Product, Source $\times$ Destination) & 0 & 0 & 0 & 0 & 0 & 0 & 0 & 0 \\
\hline $2 \times \operatorname{Cov}$ (Destination $\times$ Product, Product) & 0 & 0 & 0 & 0 & 0 & 0 & 0 & 0 \\
\hline $2 \times \operatorname{Cov}($ Destination $\times$ Product, Destination) & 0 & 0 & 0 & 0 & 0 & 0 & 0 & 0 \\
\hline Total & 100 & 100 & 100 & 100 & 100 & 100 & 100 & 100 \\
\hline
\end{tabular}

Table A8. Variance decompositions of export growth of all NON-ZERO export flows in 1998-2010 for the average country within each subset of countries. The sample is restricted to export flows that are strictly positive in both 1998 and 2010. Countries are classified as "low" export growth if their export growth is at or below the 25th percentile, "medium" if between 25th and 75th percentiles, and "high" if export growth is at or above the 75th percentile of export distribution. Data: COMTRADE.

\section{Correlates of Components of Variance Decomposition}

We regress the shares from Table 6 for top 20 exports and all export flows (including new and disappearing flows) on log GDP per capita and on the Destinations Concentration Index (both in 1998). Table A9 reports the results. Comparative advantage (Source x Product) and bilateral forces (Source x Destination) account for less of overall variance for richer countries and with more diversified countries. 


\begin{tabular}{|c|c|c|c|c|c|c|c|}
\hline \multicolumn{8}{|l|}{ A. Top 20 flows } \\
\hline & (1) & (2) & (3) & (4) & (5) & (6) & (7) \\
\hline & \multicolumn{7}{|c|}{ Dependent Variables: Percent of Variance of Export Flow Growth due to } \\
\hline & $\begin{array}{l}\text { Var(Source } x \\
\text { Product) }\end{array}$ & $\begin{array}{l}\text { Var(Source } x \\
\text { Destination) }\end{array}$ & $\operatorname{Var}$ (Product) & $\operatorname{Var}($ Destination) & $\begin{array}{l}\text { Var(Destination } \mathrm{x} \\
\text { Product) }\end{array}$ & $\operatorname{Var}($ Residual) & $\begin{array}{c}\text { Cov(Product, Source } \\
\text { x Product) }\end{array}$ \\
\hline \multirow{2}{*}{ Log GDP per capita } & $-2.822 * * *$ & $-3.256 * * *$ & $-1.343 *$ & $-0.603 * *$ & 0.175 & $4.709 * * *$ & $2.929 * *$ \\
\hline & $(0.851)$ & $(0.484)$ & $(0.784)$ & $(0.234)$ & $(0.449)$ & $(0.628)$ & $(1.346)$ \\
\hline \multirow[t]{2}{*}{ Destination Concentration Index } & $19.29 * * *$ & $11.67^{* * *}$ & -1.134 & $-3.742 * *$ & -4.535 & -6.975 & -13.88 \\
\hline & (6.385) & (3.634) & (5.883) & (1.754) & (3.371) & (4.710) & (10.09) \\
\hline \multicolumn{8}{|l|}{ B. All flows } \\
\hline & (1) & (2) & (3) & (4) & (5) & (6) & (7) \\
\hline & \multicolumn{7}{|c|}{ Dependent Variables: Percent of Variance of Export Flow Growth due to } \\
\hline & $\begin{array}{l}\text { Var(Source } x \\
\text { Product) }\end{array}$ & $\begin{array}{l}\text { Var(Source } x \\
\text { Destination) }\end{array}$ & $\operatorname{Var}$ (Product) & $\operatorname{Var}$ (Destination) & $\begin{array}{l}\text { Var(Destination } \mathrm{x} \\
\text { Product) }\end{array}$ & $\operatorname{Var}($ Residual) & $\begin{array}{c}\text { Cov(Product, Source } \\
x \text { Product) }\end{array}$ \\
\hline \multirow[t]{2}{*}{ Log GDP per capita } & $-2.962 * * *$ & $-2.574^{* * *}$ & $0.243^{* *}$ & $-1.792 * * *$ & 0.120 & $5.980 * * *$ & $0.640 * * *$ \\
\hline & $(0.514)$ & $(0.409)$ & $(0.0946)$ & $(0.309)$ & $(0.218)$ & $(0.623)$ & $(0.188)$ \\
\hline \multirow[t]{2}{*}{ Destination Concentration Index } & $17.20^{* * * *}$ & 4.801 & $-2.530^{* * *}$ & -2.424 & $-3.924 * *$ & $-15.12 * * *$ & -1.974 \\
\hline & (3.854) & (3.067) & $(0.709)$ & (2.318) & (1.637) & $(4.672)$ & (1.414) \\
\hline
\end{tabular}

Table A9. Variance shares, income and export diversification. The Table reports OLS estimates of how variance shares vary across countries with log GDP per capita and with the Destination Concentration Index. GDP data are from the World Bank's World Development Indicators. Destination Concentration Index is the weighted average of the Initial Herfindahl Index over destinations within a source exporting country, where the weights are export values. Both regressors pertain to 1998. Source for exports is COMTRADE. 